$12-2019$

\title{
Hope For Syntactic Bootstrapping
}

\author{
Kaitlyn Harrigan \\ kharrigan@wm.edu \\ Valentine Hacquard \\ Jeffrey Lidz
}

Follow this and additional works at: https://scholarworks.wm.edu/aspubs

Part of the Linguistics Commons

\section{Recommended Citation}

Harrigan, Kaitlyn; Hacquard, Valentine; and Lidz, Jeffrey, Hope For Syntactic Bootstrapping (2019).

Language, 95(4), 642-682.

https://doi.org/10.1353/lan.2019.0069

This Article is brought to you for free and open access by the Arts and Sciences at W\&M ScholarWorks. It has been accepted for inclusion in Arts \& Sciences Articles by an authorized administrator of W\&M ScholarWorks. For more information, please contact scholarworks@wm.edu. 


\section{HOPE FOR SYNTACTIC BOOTSTRAPPING}

KAITLYN HARRIGAN

William \& Mary
VALENTINE HACQUARD

University of Maryland

College Park
JEFFREY LIDZ

University of Maryland

College Park

We explore children's use of syntactic distribution in the acquisition of attitude verbs, such as think, want, and hope. Because attitude verbs refer to concepts that are opaque to observation but have syntactic distributions predictive of semantic properties, we hypothesize that syntax may serve as an important cue to learning their meanings. Using a novel methodology, we replicate previous literature showing an asymmetry between acquisition of think and want, and we additionally demonstrate that interpretation of a less frequent attitude verb, hope, patterns with type of syntactic complement. This supports the view that children treat syntactic frame as informative about an attitude verb's meaning.*

Keywords: language acquisition, syntactic bootstrapping, word learning, attitude verbs, verb learning, semantics, pragmatics

1. Introduction. Propositional attitude verbs, like think and want, are used to describe the contents of people's minds, such as their beliefs (1) or desires (2) regarding possible states of affairs.

(1) John thinks that Mary is home.

(2) John wants Mary to be home.

Because mental states do not leave reliable correlates in the physical world, acquiring the meaning of attitude verbs may be particularly challenging. Consistent with this, they tend to be acquired later than other verbs. While this delay was initially attributed to CONCEPTUAL difficulties with mental representations, mounting evidence shows that infants are surprisingly aware of the mental states of others (Onishi \& Baillargeon 2005, Southgate et al. 2007, Surian et al. 2007, Buttleman et al. 2009, Kovács et al. 2010, Knudsen \& Liszkowski 2012, He \& Lidz 2017). From the first months of life, infants give privileged status to human agents and are sensitive to the goals and perspectives of their conversation partners. They attribute goal-directedness to agents from as young as five months (Woodward 1998) and seem to track beliefs from as early as seven months (Kovács et al. 2010). This sensitivity to other minds also helps children in language acquisition. Children can track eye-gaze and use it to learn new words by sixteen months (Baldwin 1991, Bloom 2000). In their second year, infants can use their knowledge of existing words to infer that a novel noun refers to a novel object (Markman \& Wachtel 1988, Clark 1990, Mervis \& Bertrand 1994, Diesendruck \& Markson 2001, Halberda 2003). By age two, children are adult-like in their interpretation of indexical pronouns, which shift reference based on conversational roles (Moyer et al. 2015).

Given the salience of psychological states in infant reasoning and their efficacy in shaping word learning, linking psychological concepts with words may be no more difficult than linking object and event concepts with words. If, due to this richness of the learners' representations of other minds, this linking is indeed straightforward, there

* This article reports on work supported by NSF grants \#BCS-1124338 and IGERT \#0801465. We are grateful to many people who contributed to this work, including: two anonymous referees and associate editor Kristen Syrett at Language for their thoughtful comments; research assistants at the University of Maryland, including Anna Ball, Courtney Cooper, Morgan Moyer, and Ashley Tipton; Deb Harrigan for experimental materials; and audiences at MACSIM 5, LSA 2015, GALANA 6, SRCD 2015, WCCFL 33, and BUCLD 40. 
should be no CONCEPTUAL barrier to learning attitude verbs. Yet learners still have to realize that attitude verbs refer to mental states. Because there are no obvious physical cues for thinkings or wantings, information other than the physical context of use may be required to learn their meanings. The syntactic bootstrapping hypothesis (Landau \& Gleitman 1985, Gleitman 1990) holds that the syntactic context provides one relevant source of information that children can use in identifying verb meanings. If attitude verbs depend on the syntactic context to be learned, we can expect syntactic development to function as a bottleneck on their acquisition.

Attitude verbs represent the paradigm case for the bootstrapping hypothesis because (i) the physical contexts in which they are used provide so little evidence about their meanings (Gleitman 1990, Gillette et al. 1999), and (ii) their syntactic distributions are highly restricted (Landau \& Gleitman 1985). But while attitudes provide the strongest argument for the plausibility of syntactic bootstrapping, evidence for it is thin on the ground. Most of the evidence for syntactic bootstrapping has focused on simple action verbs (Pinker 1989, Naigles 1990, 1996, Lidz et al. 2003, Scott \& Fisher 2009, Yuan \& Fisher 2009, Fisher et al. 2010). In this article, we show that children make use of syntactic cues to figure out attitude-verb meanings.

Propositional attitude verbs are so called because they are taken to express the 'attitude' of an individual toward a proposition or state of affairs. The acquisition literature typically focuses on those attitude verbs that express mental states, such as want and think, because their meanings are arguably the ones with the fewest cues from the situational context. In the present discussion, however, we can understand the term more broadly to extend to all predicates that relate an individual (expressed by their subject) to a proposition (expressed by a sentential complement), including also verbs of communication (say, tell) and perception (see, hear). ${ }^{1}$

Syntactic information could be useful for attitude-verb acquisition at both a broad and a narrow level. At a broad level, a verb taking a sentential complement at all, as in 3 , might be a good initial cue that the verb describes an attitude, broadly construed, but not an action. And indeed, several experimental findings suggest that the presence of a sentential complement could help learners distinguish attitude verbs as a class from other verbs (Landau \& Gleitman 1985, Gleitman 1990, Fisher et al. 1991, Lidz et al. 2003, Gleitman et al. 2005, Papafragou et al. 2007).

(3) John kertunks that Mary is home.

But syntactic distribution could play a role in alerting the learner not just to the fact that the verb expresses an attitude, but also to the KIND of attitude it expresses. Wantings and thinkings typically cooccur (e.g. John's desire for Mary to be home spatially and temporally coincides with his believing that she is not with him), and so here again, information other than the physical context may be required to figure out what mental state is being referred to. Again, syntax could provide useful cues. As seen in 1-2 above, the complements of think and want differ: the complement of think is finite, that of want nonfinite; compare 4-5.

(4) *John thinks Mary to be home.

(5) *John wants that Mary is home.

\footnotetext{
${ }^{1}$ We leave aside modals (e.g. must, can) and verbs that do not allow an overt subject in their complement (e.g. begin, try, seem), though related learnability issues arise. For ways in which syntactic bootstrapping could be relevant in their acquisition, see Becker \& Estigarribia 2013 and van Dooren et al. 2017.
} 
Assuming that this kind of syntactic selection tracks a meaningful semantic distinction, children may be able to exploit it when learning attitude-verb meanings.

Promisingly, the syntax and semantics literature argues for a principled link between attitude meaning and attitude syntax. Crosslinguistically, attitude verbs tend to split into two main classes: verbs that express desires - and preferences more generally-like want (PREFERENTIAL ATTITUDES), and verbs that express beliefs - and judgments of truth more generally-like think (REPRESENTATIONAL ATTITUDES), and this split is tracked by syntactic selection (Bolinger 1968, Searle \& Vanderveken 1985, Villalta 2000, 2008, Anand \& Hacquard 2013, among others). However, while the same split tends to be found crosslinguistically, its syntactic correlates differ across languages. In French, for instance, the complements of think's and want's counterparts are both finite, but the former is in the indicative mood, as in 6, and the latter in the subjunctive mood, as in 7. How can the learner know what syntactic properties to attend to in their language when figuring out attitude-verb meanings?

(6) Jean pense que Marie est à la maison.

Jean thinks that Marie is.IND home

'Jean thinks that Marie is home.'

(7) Jean veut que Marie soit à la maison.

Jean wants that Marie be.subJ home.

'Jean wants Marie to be home.'

Hacquard and Lidz (2019) propose that while languages differ in the particular syntactic correlates to the preferential/representational split, they converge at an abstract level in that complements of representational attitudes show syntactic hallmarks of declarative main clauses: in Romance languages, for instance, declarative main clauses are in the indicative mood; in English, they are finite. If learners expect a link between declarative syntax and representationality, they could exploit syntactic features such as mood, in French, or finiteness, in English, to infer that the embedding verb expresses a belief vs. a preference (for supporting computational evidence for the feasibility of this bootstrapping hypothesis, see White et al. 2018).

Initial evidence that children are sensitive to the syntax of attitude reports comes from the fact that they systematically distinguish want and think early on. Children start producing want to express desires as young as eighteen months (Bartsch \& Wellman 1995). They further seem to understand want sentences by around age three (Wellman \& Bartsch 1988, Wellman \& Wooley 1990, Wellman \& Banerjee 1991, Bartsch \& Wellman 1995, Repacholi \& Gopnik 1997, Harrigan et al. 2018), even when the desired outcome conflicts with reality or with the child's own desires (Moore et al. 1995, Rakoczy et al. 2007, Rakoczy 2010, Harrigan et al. 2015, Harrigan et al. 2018). This requires that the concept of desire be readily available to very young children, that they be proficient at tracking others' minds, and that their sophisticated cognitive capacities allow them to link the word want to the desire concept with relative ease. For think, however, we see a different trajectory. Many studies find that children have difficulty understanding think sentences that report a false belief well into their fourth year (Johnson \& Maratsos 1977, Wimmer \& Perner 1983, de Villiers \& de Villiers 2000, Wellman et al. 2001, de Villiers \& Pyers 2002, Perner et al. 2003, de Villiers 2005, 2007). A number of hypotheses address this think-want asymmetry in acquisition: some invoke conceptual differences (Perner et al. 2003, Perner et al. 2005, Perner \& Ruffman 2005), others, differences in syntactic and semantic complexity between the verbs (de Villiers \& de Villiers 2000, 2009, de Villiers 2007), and others still, pragmatic differences in how these verbs are typically used (Lewis et al. 2012, 2017, Hacquard 2014, Hacquard \& Lidz 
2019). Regardless of the explanation, children differentiate want from think early. This suggests that some aspect of a child's experience reveals that think and want belong to different semantic classes, even at a stage when they have not fully mastered their meanings. And given the lack of nonlinguistic cues, this part of children's experience with the words could well be their syntactic distribution.

In this article, we directly test children's sensitivity to syntactic cues when interpreting attitude verbs and provide evidence for the viability of the syntactic bootstrapping hypothesis for attitude verbs. In $\S 2$, we review the literature on the syntax and semantics of attitude reports, which argues for a principled link between the two, and spell out a syntactic bootstrapping account. We present in $\S 3$ a series of experiments testing children's understanding of an unfamiliar attitude verb, hope, comparing it to think and want. We exploit the fact that hope takes both finite and nonfinite complements. The syntactic bootstrapping hypothesis predicts that children will use syntax as evidence about the meaning of unfamiliar attitude verbs, and in particular, that nonfinite complements should lead to desire-like interpretations (like want), while finite complements should lead to belief-like interpretations (like think). In experiments 1 and 2, we compare children's interpretation of think and want sentences in an experimental set-up that makes both beliefs and desires salient. We find that four-year-olds are adult-like with want and influenced by reality with think, reproducing past findings. Experiments 3 and 4 test children's comprehension of hope. We find that children are sensitive to syntactic frame, interpreting hope sentences differently depending on the complement: children are lured by reality with hope with a finite complement, as with think, but not with a nonfinite complement, as with want.

2. A SYNTACTIC BOOTSTRAPPING HYPOTHESIS FOR ATTITUDE VERBS: BELIEF VS. DESIRE. In this section, we briefly review this think-want asymmetry in acquisition, and explanations from the literature. We then establish the link between belief and desire attitudes and their syntactic distributions, and present a syntactic bootstrapping proposal for attitudes.

2.1. THINK-WANT ASYMMETRY IN ACQUiSition. Until at least age four, children make consistent errors with think sentences used to report false beliefs (Johnson \& Maratsos 1977, de Villiers 1995, de Villiers \& de Villiers 2000, de Villiers \& Pyers 2002, Sowalsky et al. 2009). In a context where John thinks that Mary is home, but she is really away, children typically reject a sentence like 1 (John thinks that Mary is home). They do not, however, make the same error with want sentences. In a context where John wants Mary to be home, but she is really away, children typically accept a sentence like 2 (John wants Mary to be home). In both cases, if Mary happens to be home in reality, John has a mental state about the world that conflicts with reality. Despite conflicts in both cases, three-year-olds are adult-like in assessing the want sentence, while being consistently lured by reality with the think sentence, seemingly responding to the truth value of the complement, rather than that of the whole sentence (the attitude ascription).

The traditional explanation for this asymmetry from the developmental psychology literature is that it reflects an asymmetry in their grasp of the underlying concepts. Children are said to acquire the DESIRE concept early, while the BELIEF concept awaits the development of full theory of mind, around age four (Perner et al. 2003, Perner et al. 2005, Perner \& Ruffman 2005, among others). The relative delay of the belief concept could also be due to less exposure to explicit reference to belief vs. desire, or greater processing demands for beliefs than for desires (see Moore et al. 1995, Rakoczy et al. 2007, Rakoczy 2010). For de Villiers and colleagues (de Villiers \& de Villiers 2000, 
2009, de Villiers 2007), the development of the belief concept is enabled by the grammatical development of the type of complement that verbs like think or say select for, namely finite complements, which can be true or false. Mastering this kind of structure, in which a false sentence can be embedded under a true one, gives children the conceptual scaffolding to represent false belief.

That children independently struggle with the belief concept until age four is supported by hundreds of explicit false-belief tasks (for a meta-analysis, see Wellman et al. 2001). However, numerous infant studies in the last fifteen years have cast doubt on the conceptual hypothesis, by showing that infants as young as seven months show surprise when protagonists act in ways that are inconsistent with their beliefs, whether these beliefs are true or false (Onishi \& Baillargeon 2005, Southgate et al. 2007, Kovács et al. 2010 , among others). While the exact nature of the disconnect between infants' performance on such implicit false-belief tasks and that of older children on explicit tasks is under debate, a growing number of researchers take the former to truly reflect children's conceptual competence and blame factors other than conceptual deficiency-such as additional task demands - to explain older children's consistent failures (Hansen 2010, Rubio-Fernández \& Geurts 2013, Helming et al. 2014).

But even putting aside infants' conceptual abilities, we find that three- and four-yearolds' mastery of think has been underestimated by the traditional experimental set-up in which they are typically tested. Through a series of experiments, Lewis argues that children's apparent difficulty with think is not conceptual or semantic, but pragmatic in nature (Lewis, Hacquard, \& Lidz 2012, 2017). Children have access early on to an adult-like representation of think and the underlying belief concept, but their competence is masked by difficulty untangling what speakers intend to convey when USING think sentences.

Adult speakers often use think sentences to indirectly assert the complement clause. This happens with so-called parenthetical uses of think (Urmson 1952, Hooper 1975), where the main point of the utterance is carried by the complement, and the main clause serves an evidential role (Simons 2007). To see this, consider a context where we are wondering where Mary is.

(8) A: Where is Mary?

B: John thinks that she's in DC.

C: No, she's in Baltimore.

In this context, the main point of B's utterance is that Mary is in DC, and, as C's response indicates, $\mathrm{C}$ can directly reject this indirect assertion: $\mathrm{C}$ is not denying that John holds a particular belief; rather, she is rejecting the claim that Mary is in DC. Lewis et al. argue that children's rejection of false-belief sentences is due to their assuming such indirect assertions, even in cases where adults do not, and they provide experimental evidence in support of this view.

To block indirect-assertion uses, Lewis et al. (2012) manipulated the salience of the reporting belief by contrasting false-belief situations in which one 'seeker' has a belief about a hider's location with cases where two 'seekers' have conflicting beliefs about the hider's location. In the two-seeker condition, performance of four-year-olds significantly improved. To see whether children could access the literal meaning of think sentences, Lewis et al. (2017) tested whether three-year-olds are able to reject a think sentence whose literal meaning was false. In a typical false-belief scenario, in which Dora thinks that Swiper is behind the toy box but Swiper is really behind the curtain, children reject the sentence Dora thinks that Swiper is behind the toy box (because they cannot attribute to Dora a false belief, according to the traditional conceptual hypothe- 
sis, and because they assume an indirect assertion that Swiper is behind the toy box, according to the pragmatic hypothesis). Lewis et al. introduce a further condition: in the same scenario, children are asked to evaluate the sentence Dora thinks that Swiper is behind the curtain. This sentence is literally false (Dora does not hold this belief), but the complement is true: Swiper is behind the curtain. According to the conceptual hypothesis, children should accept this sentence: if children cannot attribute to Dora a false belief, they have to assume that she thinks that Swiper is behind the curtain, since that is where he is. According to the pragmatic hypothesis, children have access to both the literal and the enriched meanings of think sentences. They should thus be able to reject this think sentence based on its false literal meaning. This is exactly what was found, suggesting that even three-year-olds have access to the literal meaning of think, and thus the underlying concept, and that their errors are mostly pragmatic: they do not have trouble figuring out what think sentences mean, but rather what SPEAKERS mean when they use think sentences. Note that, building on Lewis et al. 2012, Lewis et al. 2017 exclusively used two-seeker scenarios in order to increase the salience of the reported belief and optimize young children's performance.

2.2. THINK-WANT ASYMMETRY IN SYNTAX/SEMANTICS. Attitude verbs have been argued to fall into two main semantic classes: Bolinger's 'representationals', ${ }^{2}$ which express judgments of truth, such as think or say, and 'preferentials', which express preferences such as want or wish (Bolinger 1968, Searle \& Vanderveken 1985, Villalta 2000, 2008, Anand \& Hacquard 2013, among others). That representationals - but not preferentials - express judgments of truth, which can be endorsed, can be seen with the following contrast (Pesetsky 1992).

(9) a. John \{thinks, said\} that Mary is in DC, which is true.

b. John \{wants, ordered Mary to be in DC, \#which is true.

As we saw in the preceding section, speakers can indirectly endorse such judgments of truth, resulting in indirect assertions of the complement. Such indirect-assertion uses are not as routinely available with preferentials like want.

(10) A: Where is Mary?

$\mathrm{B}_{1}$ : John thinks she's in DC.

$\mathrm{B}_{2}$ : ??John wants her to be in DC.

The felicity of $\mathrm{B}_{2}$ 's answer requires more contextual support: somehow, it has to be that John has authority over Mary's actions (e.g. John is Mary's boss), and thus whatever John wants, Mary does. If John has no say in Mary's whereabouts, $\mathrm{B}_{2}$ 's utterance does not seem appropriate. A more routine indirect speech act for desire verbs like want is indirect command (Searle 1975).

(11) I want you to go to your room.

Sentence 11 is literally a desire report, but it is routinely used as an indirect command (go to your room!). We thus see that think and want belong to two different semantic classes of attitude verbs: those that express judgments of truth (representationals), which are routinely used for indirect assertions (whereby the speaker endorses the judgment of truth expressed), and those that express preferences (preferentials), which are routinely used for indirect commands (whereby the speaker endorses the preference expressed).

The formal linguistic literature on selection has argued extensively that this split in representationality is tracked by syntactic selection in different languages. In Romance

\footnotetext{
${ }^{2}$ The term 'representational' refers to the fact that attitude verbs like think present a 'picture of the world'.
} 
languages, for instance, representationals select for complements in the indicative mood, while preferentials select for complements in the subjunctive mood, as shown in 6 and 7 above for French (Bolinger 1968, Hooper 1975, Farkas 1985, Giannakidou 1997, Villalta 2008, Anand \& Hacquard 2013, among others). In English, representationality is also tracked syntactically: representationals typically take finite complements, and preferentials nonfinite complements, as we saw in $1-2 .{ }^{3}$ In German, the split is tracked by word order. Typically, embedded clauses in German are verb-final. However, representationals, but not preferentials, allow the verb to appear in second position (Truckenbrodt 2006, Scheffler 2008).

(12) a. Maria denkt, dass Peter heute kommt.

Maria thinks that Peter today comes

b. Maria denkt, Peter kommt heute.

Maria thinks Peter comes today

'Mary thinks that Peter is coming today.'

(13) a. Maria will, dass Peter heute kommt.

Maria wants that Peter today comes

b. *Maria will, Peter kommt heute.

Maria wants Peter comes today

'Mary wants Peter to come today.'

Thus, in English, Romance, and German, syntactic distribution may serve as a cue as to whether a given attitude verb falls into the representational or the preferential class, though the cue differs across languages. This may at first blush seem to be problematic for a bootstrapping learning strategy, as learners cannot anticipate the particular features specific to their language. However, although the specific features associated with both semantic classes differ crosslinguistically, they seem to converge at an abstract level (Hacquard \& Lidz 2019): the complements of representationals, but not preferentials, allow syntactic features found in declarative main clauses in that language, the clause type typically used for assertions: indicative mood for Romance, finiteness for English, verb-second for German. Thus, at the right level of abstraction, syntax tracks representationality in ways that might be useful to the learner.

2.3. A SYNTACTIC BOOTSTRAPPING HYPOTHESIS FOR ATTITUDES. We propose that syntax plays a crucial role in helping the learner map attitude verbs into two main semantic classes: those that express judgments of truth (representationals), and those that express preferences (preferentials). This is because there is a principled link between these two semantic classes and the type of syntactic complement they select for: representationals take complements with syntactic hallmarks of declarative main clauses, and preferentials do not - their complements instead resemble imperative clauses.

The acquisition trajectory could look as follows: SYNTAX helps the learner map a novel attitude verb into one of two SEMANTIC classes: belief vs. desire. Each SEMANTIC class leads to different routine PRAGMATIC enrichments in the form of indirect speech acts: indirect assertions for the former (endorsement of a judgment of truth) vs. indirect commands for the latter (endorsement of a preference). The former, but not the latter, lead to reality-based errors, when the child rejects an indirect assertion that she knows

\footnotetext{
${ }^{3}$ Bolinger (1968) argues that the syntactic feature in English that correlates with mood selection in Romance is complement preposing. Representationals allow preposing (John is home, I think); preferentials do not (\#John to be home, I want). Here we focus on finiteness, which also tracks representationality (see White et al. 2014, White et al. 2018).
} 
to be false. Take the case of think. Think takes complements with syntactic hallmarks of declarative main clauses. From this, the learner can infer that it must express some judgment of truth. This judgment of truth can be endorsed by the speaker, resulting in the indirect assertion of the complement. When a child hears a think sentence, she assumes that the speaker intends to indirectly assert the complement, and she rejects it, if she knows it to be false. As Lewis et al. show, this pragmatic preference can be overridden in the right context. With want, children do not assume indirect assertions (they may, however, assume indirect commands, which do not get in the way of truth-value judgment tasks that are typically used to test children's comprehension of attitude verbs). Hence, pragmatics does not get in the way: children accept reports of a desire that conflicts with reality.

Why should children so routinely assume indirect-assertion uses with verbs like think? Here we believe that the parallel between the syntax of the complement and the type of speech act for which this syntax is typically used is not accidental. Verbs like think take complements with declarative syntax, the syntax typically used for assertions, and think sentences are routinely used for INDIRECT assertions. Verbs like want, by contrast, do not take such complements.

This syntactic bootstrapping hypothesis makes the following predictions for novel attitude verbs. Upon hearing an unfamiliar attitude verb, children will exploit the syntactic frame in which it appears. We expect that, all else being equal, upon hearing a verb with a finite complement in English, children will assume a representational (belief) meaning for that verb. By default, they will assume an indirect-assertion use, leading to reality-based errors. With a nonfinite complement, they will assume a preferential (desire) meaning. This meaning does not typically lend itself to an indirect-assertion use; hence children will not make reality-based errors. We test these predictions in the next section.

Note that while we focus on finiteness in this article, we do not assume a one-to-one correspondence between finiteness and representationality, or between nonfiniteness and preferentiality. Indeed, nonfinite clauses can appear with various verbs beyond preferentials, including causatives (make) and implicatives (manage), and also in the complements of some representationals like believe and expect. Our linking hypothesis is between declarative syntax (rather than finiteness) and representational semantics: the more syntactic hallmarks of declarative clauses there are in a verb's complement, the more likely the verb is to be representational. The reason we focus on finiteness is that it is the most prominent main-clause syntactic feature among the most common attitude verbs in speech to English-learning children: we therefore expect it to be one of the most noticeable frames, and thus use it as our starting point to test the viability of syntactic bootstrapping for attitude verbs (for a more in-depth discussion of the correspondence between syntactic and semantic features in the attitude domain, see White et al. 2014, White et al. 2018, White \& Rawlins 2018, and references therein).

3. Testing the SYNTACTIC BOOTSTRAPPING hyPOTHESIS FOR ATTITUde VERBS: THINK, WANT, HOPE. Syntactic bootstrapping provides a plausible explanation for how children first categorize think and want: their syntactic distribution might alert the learner that they belong to two separate semantic classes, representational vs. preferential. To demonstrate the validity of this hypothesis, we need to show that children are sensitive to syntax when learning a novel attitude verb. Both think and want are very clear examples - syntactically and semantically — of the representational and preferential subclasses. Want expresses only a desire; think expresses only a belief. Further- 
more, their syntactic distributions are complementary. We focus here on the less straightforward verb hope.

Hope shares semantic and syntactic properties with both. Syntactically, we observe distributional facts that are consistent with both classes. Hope can take both nonfinite (14) and finite (15) complements.

(14) John hopes (for Mary) to be home.

(15) John hopes that Mary is home.

Hope also shares meaning components with both classes. Hope has an obvious desire component: it always expresses a preference, regardless of syntactic frame. In the above sentences, the subject desires the content of the embedded clause. Hope also seems to have a belief component (Portner 1992, Scheffler 2008, Anand \& Hacquard 2013): the complement has to be a doxastic possibility for the subject. In a scenario where Mary is away, and John knows this, John can still want her to be home, but it is infelicitous to say that he hopes that she is home (16-17). Thus, think expresses a commitment to truth, hope expresses a commitment to the possibility of truth, and want expresses neither.

(16) John knows Mary is away, but he wants her to be home.

(17) \#John knows that Mary is away, but he hopes she's home.

These facts suggest that syntactic distribution might track semantic features, even in the case of hope: hope can take both finite and nonfinite complements, and both belief and desire meaning components are present. For our syntactic bootstrapping hypothesis to hold, the learner must be able to use the syntax to get to the semantics. We will now see why hope is an ideal case for investigating this.

Think and want are quite common in the input. In the CHILDES database (MacWhinney 2000), we found that want occurs 22,012 and think 10,187 times per million utterances. Hope is much less frequent, occurring at a rate of 364 times per million utterances. The syntactic distribution of hope and its low rate of occurrence in childdirected speech make it a good candidate for a bootstrapping study. Children are less likely to fully know its meaning by the age of four, and may therefore still be flexible in their interpretation. However, because it is a real word, it has the advantage of being somewhat familiar, not causing confusion during the experiment, ultimately allowing for the closest comparisons to our want and think studies. The fact that it occurs with both kinds of complements also allows us to manipulate syntactic frame without using ungrammatical sentences.

Cases like hope may also be informative about the syntactic bootstrapping mechanism. Want and think occur in complementary distribution; therefore if children are sensitive to the link between syntax and semantics, the subclass of these verbs may be clear from just a few occurrences. Verbs like hope present a more complicated learning challenge. The learner must track syntactic information across multiple uses of the verb and link this distributional information to semantic properties. Children have been shown to utilize distributional information across multiple frames to learn verb meanings (Naigles 1996); it is therefore possible that they also use distributional information to hypothesize fine-grained semantic information about attitude verbs. Our first step, however, is to determine whether children are sensitive to syntactic frame AT ALL in hypothesizing attitude-verb meaning. We thus restrict our current work to the finiteness distinction. Future work will continue to explore the extent to which children can glean attitude meanings from a more varied syntactic distribution.

We now present a series of experiments testing children's comprehension of want, think, and hope. Previous research shows that children have difficulty with think but not 
want, in particular when the complement is false. Thus, in contexts in which the shape under consideration is not a heart, children would typically reject 18, but accept 19 .

(18) Froggy thinks that it's a heart.

(19) Froggy wants it to be a heart.

Our experimental set-up makes both beliefs and desires salient, and these are sometimes in line with reality and sometimes counter to it. Our goals with experiments 1 and 2 are to (i) reproduce the think/want asymmetry within a single experimental paradigm, and (ii) establish patterns of responses to desire (want) and belief (think) verbs, which we use to compare to the hope responses in experiments 3 and 4 . In experiments 3 and 4 , we test children's comprehension of hope and manipulate complement type (finite as in 20, nonfinite as in 21) to see if it influences interpretation.

(20) Froggy hopes that it's a heart.

(21) Froggy hopes to get a heart.

We predict that children's responses to hope sentences should be influenced by syntactic frame: with a finite complement (20), children should give think-like responses: they should be lured by reality, and reject such sentences when the shape is actually a star. With a nonfinite complement (21), children should give want-like responses: they should not be lured by reality, and thus accept such sentences even when the shape is actually a star.

We must also address the shift in nonfinite complements between want (19) and hope (21). While it would be ideal to keep the nonfinite frame consistent throughout, hope does not occur with an embedded subject like want can (19). We wanted to use the slightly more complex want frame in experiments 1 and 2 to ensure that, if we find adult-like performance on want but not think, as we predict, we can be sure that success is not solely due to the simpler structure of a subject-less embedded clause in the complement of want. Experiments 1 and 2 will show that children CAN get a desire interpretation even with the more complex embedded subject syntax, thus ruling out this complexity as the driving force.

3.1. EXPERIMENT 1. While many studies have made claims about children's understanding of want vs. think, few directly compare them. In experiment 1 , we test want and think in a single task that makes both beliefs and desires salient.

SubJects. Participants were forty-eight children aged $4 ; 0$ to $5 ; 0$ (mean $=4 ; 6$ ). Six additional children were excluded, four due to getting too many controls incorrect, one due to parental report of the child's exposure to English as less than $80 \%$, one due to experimenter error. To be included, children needed to complete the experiment and get six of the eight controls correct. Children were recruited from the greater Washington, DC, area and tested in the Project on Children's Language Learning lab at the University of Maryland.

Design AND materials. To manipulate verb (want vs. think), we set up a game in which both the beliefs and desires of a character are relevant. The child plays with a puppet, 'Froggy'. The child and one experimenter are behind an occluder, while Froggy is on the other side. In front of the child is a box with forty colored hearts and stars. Color is predictive of shape: fifteen hearts are red and five are yellow, and fifteen stars are yellow and five are red. In the game, the experimenter pulls shapes out of the box to show Froggy. When the shape is a heart, the child gives Froggy a sticker; therefore his desire on every trial is for a heart. On each trial, before Froggy sees what the shape is, he sees a 'clue', which is ambiguous in shape. There is an opening in the occluder 
through which Froggy is shown a point - either the point of the heart or one of the points of the star (Figure 1). ${ }^{4}$

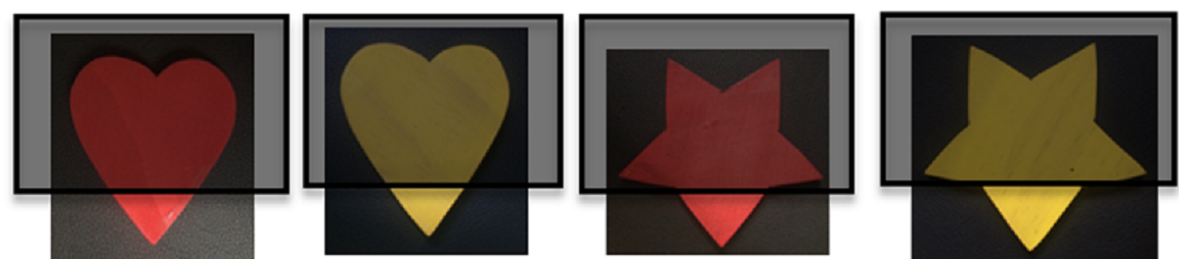

FIGURE 1. All four shape and color combinations and the 'point' that is revealed to the puppet during the clue phase.

On every trial, Froggy has both a DESIRE about the shape- because he always wants the shape to be a heart, and a BELIEF-because whenever it is red he thinks it is a heart, and when it is yellow he thinks it is a star. This set-up allows another puppet, 'Booboo', who the child is told is 'silly and wants to learn how to play the game, but often gets things mixed up', to utter test sentences about either what Froggy thinks (22) or what he wants (23).

(22) Froggy thinks that it's a heart/star.

(23) Froggy wants it to be a heart/star.

The child's job in the task is then to say whether Booboo is correct or incorrect.

In a $2 \times 4 \times 2$ design, we tested Verb as a between-subjects factor (want $(n=24)$, think $(n=24)$ ), and Condition (red heart, red star, yellow heart, yellow star) and Mentioned shape (heart vs. star) as within-subjects factors. The child's response of 'yes' or 'no' was the dependent measure. On every trial, Froggy had both a belief and a desire about the next shape. His belief was dictated by the color of the clue. When color correctly predicted shape (red heart and yellow star conditions), his belief was true. When it did not (red star and yellow heart), his belief was false. Similarly, his desire for a heart was sometimes fulfilled (heart conditions), and sometimes unfulfilled (star conditions). Booboo, the silly puppet, uttered test sentences about Froggy's beliefs (22) or desires (23) about getting a heart (Mentioned heart) or star (Mentioned star). This set-up allows for an ideal comparison of interpretation of think and want sentences-in both cases, the child is asked to reason about a mental state (belief or desire) which may conflict (false belief/unfulfilled desire) or be consistent (true belief/fulfilled desire) with reality. The goal is to see whether children have more difficulty with conflicting beliefs than desires, as in previous literature. In the study, the participant encounters every possible combination of true/false beliefs and fulfilled/unfulfilled desires. The experiment includes four items of each type, for a total of thirty-two test items per child. Table 1 shows all sixteen conditions.

Procedure. Each child was tested in a quiet room with two experimenters. One experimenter sat next to the child and gave the instructions about the game. This experimenter controlled the silly puppet, Booboo, and delivered the test sentences. The second experimenter sat on the other side of the occluder and played Froggy (Figure 2).

The second experimenter also coded the child's responses. Permission was obtained from parents to videorecord each subject in case any responses were missed during the

\footnotetext{
${ }^{4}$ Note that this figure and the next are presented in color in the electronic versions of this article, but in black and white in the print version.
} 


\begin{tabular}{|c|c|c|}
\hline \multirow{4}{*}{ think } & $\begin{array}{c}\text { CONDITION } \\
\text { (within subjects) } \\
\text { Red heart }\end{array}$ & $\begin{array}{c}\text { MENTIONED } \\
\text { (within subjects) } \\
\text { Heart } \\
\text { Star }\end{array}$ \\
\hline & Red star & $\begin{array}{l}\text { Heart } \\
\text { Star }\end{array}$ \\
\hline & Yellow heart & $\begin{array}{l}\text { Heart } \\
\text { Star }\end{array}$ \\
\hline & Yellow star & $\begin{array}{l}\text { Heart } \\
\text { Star }\end{array}$ \\
\hline \multirow{4}{*}{ want } & Red heart & $\begin{array}{l}\text { Heart } \\
\text { Star }\end{array}$ \\
\hline & Red star & $\begin{array}{l}\text { Heart } \\
\text { Star }\end{array}$ \\
\hline & Yellow heart & $\begin{array}{l}\text { Heart } \\
\text { Star }\end{array}$ \\
\hline & Yellow star & $\begin{array}{l}\text { Heart } \\
\text { Star }\end{array}$ \\
\hline
\end{tabular}

TABLE 1. Between- and within-subjects conditions for experiment 1.

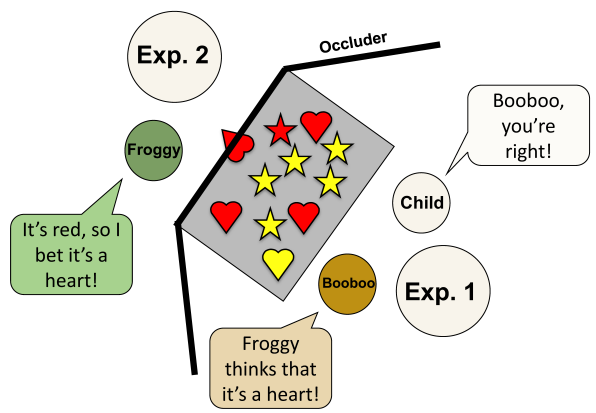

FIGURE 2. Experimental set-up.

initial coding. The experiment began by the child being introduced to Froggy: 'Hi, [child's name]. This is Froggy! We're going to play a game with Froggy today!'. The child completed several practice sessions to ensure that they understood all of the necessary elements of the game, including Froggy's desires and beliefs in this context.

PRACTICE SESSIONS. The child participated in a series of practice sessions in order to learn the set-up of the game.

Practice session \#1: Distribution. This session directs the child's attention to the distribution of colors and shapes. The shapes are divided up on the table in front of the child.

(24) 'Froggy has a whole bunch of different shapes. Let's look at what shapes he has! Can you tell me about the shapes? Some of them are red! Can you tell me what kinds of red shapes we have?' ...

'That's right! Hearts and stars! Do we have a lot of the red hearts or just a few? And what about red stars?' 
The child describes each type of shape-lots of red hearts and yellow stars, few red stars and yellow hearts. This helps them develop the intuition that a red clue is more likely to be a heart and a yellow clue is more likely to be a star, and that Froggy's guesses will reflect this.

Establishing desires. At this point we tell the child that the game will involve pulling shapes out of the box to show Froggy, and we introduce Froggy's preferences. We tell the child that Froggy 'loves getting hearts, but doesn't like getting stars at all' because every time we pull out a heart, Froggy gets a sticker. We then ask the child if they will 'help' us by being in charge of giving Froggy stickers every time we pull out a heart. This compels the child to keep track of what shapes we are pulling out, as well as motivating Froggy's preferences about shape. We check that the child remembers what Froggy 'likes' by practicing pulling out one of each shape and asking the child whether Froggy gets a sticker that time. Froggy reacts positively throughout the game every time he gets a heart (by saying things like 'Yay! I love hearts!' or 'That means it's sticker time!') and negatively when he gets a star (by saying things like 'Oh, no! Not another star!' or 'Yuck, I don't like getting stars!'). Children were very good at remembering when they should give Froggy a sticker, and they enjoyed giving the stickers and watching Froggy's reactions to getting both kinds of shapes.

Practice session \#2: Guessing game. During the next practice session, we put all of the shapes in the box, and the experimenter turns the occluder so that the child can no longer see the shapes. She then shows Froggy and the child ambiguous clues - a point sticking through a slot in the occluder. Neither the child nor Froggy can see what the shape is. The child is told that they will guess what the shape is, then Froggy will guess, and then the experimenter will take the shape out so everyone can see. If the shape is a heart, the child gives Froggy a sticker. The shapes pulled out during this session reflect the distribution in the box. This session gives the child experience seeing the ambiguous clues from Froggy's side of the occluder, and gives them the experience of having false beliefs about the shape's identity.

Establishing beliefs. This session also establishes Froggy's beliefs and motivations for those beliefs - that when the clue is red Froggy thinks it is a heart, and when it is yellow he thinks it is a star. In this session, the child sees shapes and clues matched up with the distribution of the box-helping to cement the probabilistic relations between color and shape. They also hear Froggy's 'guesses' each time, based on the clue. On each trial, Froggy looks at the clue and speculates about the shape's identity based on the color, saying 'Hmm, this time it's red, so it's probably a heart!'. This establishes Froggy's beliefs and their motivations. Froggy avoids using any mental-state verbs during all practice sessions. In the next practice session, we confirm that the child has learned this connection.

Practice session \#3: Belief check. The next practice session ensures that children understand Froggy's belief (or default guess) for each clue type. The experimenter checks this by asking the following questions:

(25) 'So when Froggy sees a red clue, what kind of shape does he guess?'

...

'And when he sees a yellow clue what does he guess?'

Children were overwhelmingly good at remembering Froggy's default guesses based on colors, but were corrected and prompted to try again if they were incorrect. 
Practice session \#4: Practice with Booboo. In the final practice session, children are introduced to the silly puppet, Booboo, who watches them play the game with Froggy. The child is told the following about Booboo.

(26) 'OK, one more thing! This is Froggy's friend, Booboo! Booboo really wants to learn how to play the game, but he's really silly and he always gets things mixed up! He always forgets what kind of shapes Froggy likes, and what kind of stuff Froggy guesses when he sees clues. But you're good at that, right? So maybe you could help Booboo learn? Booboo is going to watch us play, and sometimes he's going to try to tell us something about Froggy, but he might get it wrong, and your job is to help him out and tell him whether he's right or wrong so he can learn how to play the game.'

After Booboo is introduced, the child is told that we are going to show Booboo some clues and see what he says about Froggy. Then Booboo is shown four clues - one of each type - and says sentences about what Froggy will guess, and whether he likes that shape or not. During the time that the clue is visible only to the child, Booboo says a sentence about what Froggy will guess given the color (27), and after the shape is taken out, Booboo says a sentence about whether Froggy likes that shape (28).

(27) This one is red/yellow ... so Froggy is going to guess heart/star!

(28) Oh! Froggy likes/doesn't like that kind!

The child's job is to tell Booboo whether his statement is right or wrong. This gives the child a chance to observe that Booboo is bad at remembering Froggy's mental states and practice telling him when he is right and wrong. This session also serves as a reminder of Froggy's desires and beliefs. If children have any trouble correcting Booboo on this session, they are given help from the experimenter.

Test sentences. After the warm-up sessions are finished, the box of shapes and the occluder are turned so that the child can see which shape is under discussion. They are told that now they are going to be able to 'peek' while we show Froggy some more clues, and Booboo is still going to say something about 'what Froggy likes, or what he might guess'. Then we begin showing Froggy clues and uttering test sentences. For each trial, the experimenter chooses which shape we are going to show Froggy (often letting the child 'help' decide), and then the experimenter slides the shape into the slot so Froggy can see the clue on the other side. On the first two trials, we remind the child, 'Remember, Froggy can't see what the shape is - he can only see the point! So we have to be sneaky!'. Froggy looks at the clue, and confirms that he can see it and that he is thinking about it. He says something like 'Hmm ... this time it's red!'. After Froggy confirms that he has seen the clue, Booboo utters the test sentences. After the child responds to Booboo's utterance, we show Froggy the shape, and he responds appropriately. If it is a heart, the child gives him a sticker. Children tend to be interested and engaged throughout the entire process, which takes about twenty-five minutes.

REsults. Children's responses were coded by the second experimenter as the child delivered the response. There are three possible response patterns given the experimental set-up. Each pattern is described below, including the predicted responses in each condition consistent with each response pattern. One pattern is to interpret the sentence as describing Froggy's DESIRES. Children behaving this way should assent to sentences that mention 'heart', regardless of the actual shape and color of the shape, because Froggy always wants it to be a heart (Table 2, 'desire' column). The second pattern is responses based on Froggy's BELIEFs. Children should assent to sentences that mention 
a heart whenever the clue is red, and to sentences that mention a star whenever the clue is yellow (Table 2, 'belief' column). Finally, we may see responses based on REALITY. Children should assent to sentences in which mentioned shape and actual shape are the same, regardless of color, desire, or belief (Table 2, 'reality' column). The adult-like responses are, of course, to respond based on the puppet's desire when the sentence is about what he wants and based on belief when it is about what he thinks. Adults should never give reality-based responses. Children should show reality responses in the think conditions, and desire responses in the want conditions. Table 2 shows the predictions for all three response types; the adult-like responses in each condition are italicized. The rightmost column shows the predictions for children's responses, and the conditions in which we expect children to differ from the adult pattern are bolded.

\begin{tabular}{|c|c|c|c|c|c|c|}
\hline $\begin{array}{l}\text { VERB } \\
\text { (between subjs) }\end{array}$ & $\begin{array}{l}\text { CONDITION } \\
\text { (within subjs) }\end{array}$ & $\begin{array}{c}\text { MENTIONED } \\
\text { SHAPE }\end{array}$ & DESIRE & BELIEF & REALITY & \multirow{3}{*}{$\begin{array}{c}\text { CHILD } \\
\text { PREDICTIONS } \\
\text { Yes } \\
\text { No }\end{array}$} \\
\hline \multirow{8}{*}{ think } & \multirow{2}{*}{ 1. Red heart } & Heart & Yes & Yes & Yes & \\
\hline & & Star & No & No & No & \\
\hline & \multirow{2}{*}{ 2. Red star } & Heart & Yes & Yes & No & No \\
\hline & & Star & No & No & Yes & Yes \\
\hline & \multirow{2}{*}{ 3. Yellow heart } & Heart & Yes & No & Yes & Yes \\
\hline & & Star & No & Yes & No & No \\
\hline & \multirow{2}{*}{ 4. Yellow star } & Heart & Yes & No & No & No \\
\hline & & Star & No & Yes & Yes & Yes \\
\hline \multirow{8}{*}{ want } & \multirow{2}{*}{ 5. Red heart } & Heart & Yes & Yes & Yes & Yes \\
\hline & & Star & $\mathrm{No}$ & No & No & No \\
\hline & \multirow{2}{*}{ 6. Red star } & Heart & Yes & Yes & No & Yes \\
\hline & & Star & No & No & Yes & No \\
\hline & \multirow{2}{*}{ 7. Yellow heart } & Heart & Yes & No & Yes & Yes \\
\hline & & Star & No & Yes & No & No \\
\hline & \multirow{2}{*}{ 8. Yellow star } & Heart & Yes & No & No & Yes \\
\hline & & Star & No & Yes & Yes & No \\
\hline
\end{tabular}

TABLE 2. Predictions for all possible response types (desire, belief, reality) in experiment 1. Italicized responses in the 'desire' and 'belief' columns signify the adult-like responses for each verb: adults would give 'desire' responses when they hear sentences with want and 'belief' responses when they hear sentences with think. Bold responses in 'child predictions' column signify where we expect children to differ from the adultlike pattern, showing a typical 'false belief' error. We predict they will be adult-like when they hear want sentences, but non-adult-like when they hear think sentences in false-belief contexts.

Children's responses were measured in proportion of yes responses. Red heart items were counted as controls: because this is a case of true belief and fulfilled desire, we predict the same pattern of responses, whether based on desire, belief, oR reality. They should say yes when a heart is mentioned (29) and no when a star is mentioned (30), regardless of verb.

(29) Froggy wants it to be/thinks that it's a heart.

(30) Froggy wants it to be/thinks that it's a star.

We excluded four participants who got fewer than six of the eight red heart items correct.

ANALYSIS. In line with previous work, we find that children are adult-like with want, but influenced by reality with think. The proportions of yes responses for all conditions are shown in Table 3 and Figure 3. Bolded responses show conditions in which children's responses differed from the predicted adult-like responses. 


\begin{tabular}{|c|c|c|c|c|c|}
\hline $\begin{array}{l}\text { VERB } \\
\text { (between }\end{array}$ & $\begin{array}{c}\text { CONDITION } \\
\text { (within subjs) }\end{array}$ & $\begin{array}{l}\text { MENTAL STATE } \\
\text { STATUS }\end{array}$ & $\begin{array}{l}\text { MENTIONED } \\
\text { SHAPE }\end{array}$ & $\begin{array}{l}\text { ADULT-LIKE } \\
\text { RESPONSE }\end{array}$ & $\begin{array}{c}\text { PROPORTION YES } \\
(S D)\end{array}$ \\
\hline \multirow{8}{*}{ 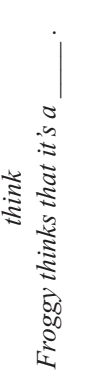 } & \multirow{2}{*}{ 1. Red heart } & \multirow{2}{*}{$\begin{array}{l}\text { True belief, } \\
\text { Fulfilled desire }\end{array}$} & Heart & Yes & $1.00(0.00)$ \\
\hline & & & Star & No & $0.03(0.17)$ \\
\hline & \multirow{2}{*}{ 2. Red star } & \multirow{2}{*}{$\begin{array}{l}\text { False belief, } \\
\text { Unfulfilled desire }\end{array}$} & Heart & Yes & $0.14(0.35)$ \\
\hline & & & Star & No & $0.85(0.40)$ \\
\hline & \multirow{2}{*}{ 3. Yellow heart } & \multirow{2}{*}{$\begin{array}{l}\text { False belief, } \\
\text { Fulfilled desire }\end{array}$} & Heart & No & $0.87(0.33)$ \\
\hline & & & Star & Yes & $0.22(0.41)$ \\
\hline & \multirow{2}{*}{ 4. Yellow star } & \multirow{2}{*}{$\begin{array}{l}\text { True belief, } \\
\text { Unfulfilled desire }\end{array}$} & Heart & No & $0.05(0.21)$ \\
\hline & & & Star & Yes & $0.91(0.31)$ \\
\hline \multirow{8}{*}{ 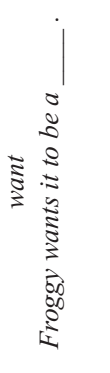 } & \multirow{2}{*}{ 5. Red heart } & \multirow{2}{*}{$\begin{array}{l}\text { True belief, } \\
\text { Fulfilled desire }\end{array}$} & Heart & Yes & $0.98(0.14)$ \\
\hline & & & Star & No & $0.04(0.20)$ \\
\hline & \multirow{2}{*}{ 6. Red star } & \multirow{2}{*}{$\begin{array}{l}\text { False belief, } \\
\text { Unfulfilled desire }\end{array}$} & Heart & Yes & $0.70(0.46)$ \\
\hline & & & Star & No & $0.17(0.37)$ \\
\hline & \multirow{2}{*}{ 7. Yellow heart } & \multirow{2}{*}{$\begin{array}{l}\text { False belief, } \\
\text { Fulfilled desire }\end{array}$} & Heart & Yes & $1.00(0.00)$ \\
\hline & & & Star & No & $0.06(0.24)$ \\
\hline & \multirow{2}{*}{ 8. Yellow star } & \multirow{2}{*}{$\begin{array}{l}\text { True belief, } \\
\text { Unfulfilled desire }\end{array}$} & Heart & Yes & $0.76(0.43)$ \\
\hline & & & Star & No & $0.16(0.36)$ \\
\hline
\end{tabular}

TABLE 3. Proportion 'yes' responses for all conditions in experiment 1 . Bolded responses signify conditions in which children's response patterns differed from the predicted adult-like pattern. The patterns differ only in the think conditions in which reality differed from the puppet's belief state, satisfying the predictions in Table 2 and replicating the classic 'false belief' error observed in other studies.
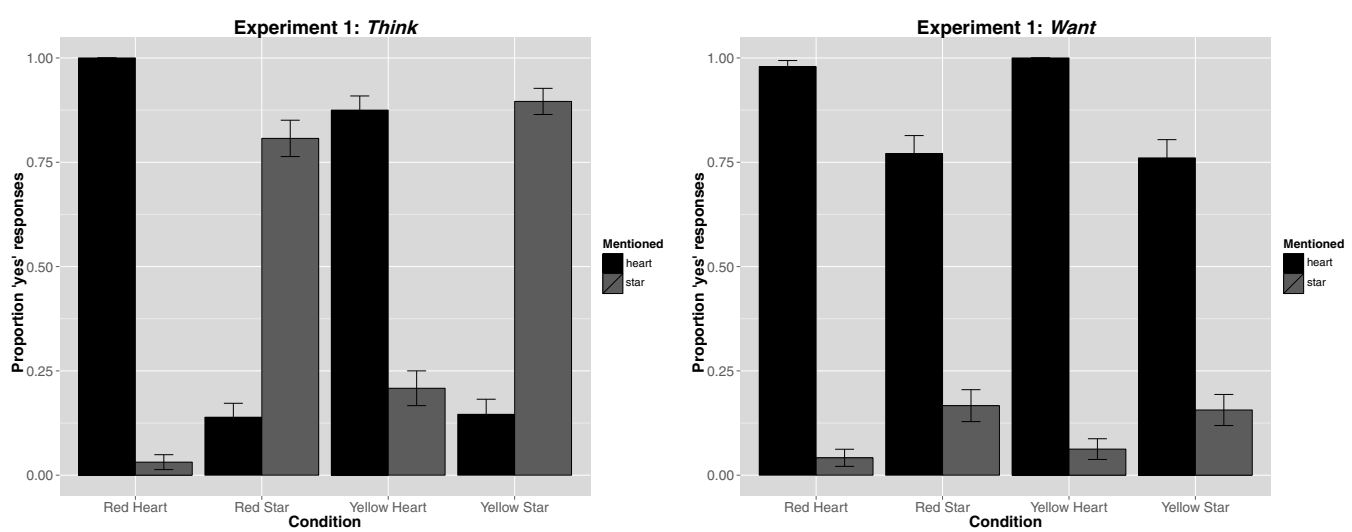

FIGURE 3. Proportion yes responses for all conditions in experiment 1. Desire responses are characterized by yes responses to mentioned heart sentences (black bars), which is the pattern observed for want sentences. Reality responses are characterized by yes responses when the mentioned shape matches the actual shape, which is the pattern observed for think sentences.

Children are adult-like in their responses to want, which match the 'desire' predictions, but not to think sentences, which match the 'reality' predictions.

Statistical anAlysis of EXPERIMENT 1 . We used generalized linear mixed-effects models to analyze the results. These models are well suited for analyzing categorical data (Baayen 2008, Jaeger 2008). The reported models have random intercepts. These 
models predict the probability of a specific response (a correct answer) in the different conditions (see Agresti 2002, Jaeger 2008). We ran a mixed-effect logit model with yes responses as the dependent measure, with Verb, Mentioned, and Condition as fixed effects, and Subject as a random effect. We find a three-way interaction of Verb, Mentioned, and Condition $\left(\chi^{2}(1)=28.65, p<0.0001\right)$, showing different patterns of responses across each of the Verb conditions. We then look at each verb separately to best understand interpretation patterns. In the following sections, we describe the models we ran for each Verb condition.

STATISTICAL ANALYSis of THINK CONDitions. For the think conditions, we again ran a mixed-effect logit model with yes responses as the dependent measure, with Mentioned and Condition as fixed effects, and Subject as a random effect. We find a significant twoway interaction between Mentioned and Condition $\left(\chi^{2}(1)=224.28, p<0.0001\right)$, so we analyze each level of Condition separately. We ran four pairwise comparisons over each Condition/Mentioned pair. We find that in the heart conditions, children are significantly more likely to say yes to a mentioned heart and no to a mentioned star. In the star conditions, children are significantly more likely to say yes to star and no to heart. Estimated marginal means and $p$-values for each condition are reported in Table 4.

\begin{tabular}{|c|c|c|c|}
\hline CONDITION & PROBABILITY Y & RESPONSE $(S E)$ & $p$-VALUI \\
\hline & Mentioned heart & Mentioned star & \\
\hline Red heart & $0.99(0.01)$ & $0.02(0.01)$ & $<0.0001$ \\
\hline Red star & $0.12(0.03)$ & $0.83(0.05)$ & $<0.000$ \\
\hline Yellow heart & $0.89(0.03)$ & $0.18(0.05)$ & $<0.0001$ \\
\hline Yellow star & $0.12(0.04)$ & $0.91(0.03)$ & $<0.000$ \\
\hline
\end{tabular}

TABLE 4. Pairwise comparisons of probability yes responses across think conditions. In heart conditions, children are significantly more likely to give yes responses to mentioned hearts than mentioned stars. In star conditions, children are more likely to give yes responses to mentioned stars than mentioned hearts.

For all conditions, children are more likely to give yes responses when the shape mentioned matches the shape in the condition. This replicates previous studies investigating think: children are influenced by reality, giving yes responses only when the mentioned shape matches the actual shape.

STATISTICAL ANALYSis of WANT CONDITIONS. For the want conditions, we ran a mixed-effect logit model with yes responses as the dependent measure, with Mentioned and Condition as fixed effects, and Subject as a random effect. In this model, we find a main effect of Mentioned $\left(\chi^{2}(1)=66.76, p<0.0001\right)$, showing that children respond differently when heart is mentioned than when star is mentioned, consistent with desire interpretations for want sentences. We also find a significant two-way interaction between Mentioned and Condition $\left(\chi^{2}(1)=40.37, p<0.0001\right)$, suggesting that we should analyze each level of Condition. We ran four pairwise comparisons over each Condition/Mentioned pair. We find that for all conditions, children are significantly more likely to say yes when heart is mentioned and no when star is mentioned. Estimated marginal means and $p$-values for each condition are reported in Table 5.

\begin{tabular}{|c|c|c|c|}
\hline CONDITION & PROBABILITY $Y L$ & RESPONSE $(S E)$ & $p$-VALUE \\
\hline & Mentioned heart & Mentioned star & \\
\hline Red heart & $0.99(0.01)$ & $0.02(0.01)$ & $<0.0001$ \\
\hline Red star & $0.74(0.06)$ & $0.14(0.05)$ & $<0.0001$ \\
\hline Yellow heart & $0.99(0.01)$ & $0.04(0.02)$ & $<0.0001$ \\
\hline Yellow star & $0.80(0.05)$ & $0.13(0.04)$ & $<0.0001$ \\
\hline
\end{tabular}

TABLE 5. Pairwise comparisons of probability yes responses across want conditions. In all conditions, children are significantly more likely to give yes responses to mentioned hearts than mentioned stars. 
The statistical models support our overall conclusion: children are overwhelmingly responding to want sentences based on Froggy's desires - they respond differently based on whether heart or star is mentioned in the test item.

The interaction between Mentioned and Condition demonstrates, however, that children are not completely adult-like in their responses to want sentences: they are more likely in some conditions to give yes responses to mentioned hearts. To better understand this interaction, we also ran pairwise comparisons within each of the Mentioned levels. In this analysis, we compare the likelihood of yes responses across each possible combination of conditions. When heart is mentioned, children are equally likely to give yes responses across both heart conditions and equally likely to give yes responses across both star conditions; but they are more likely to give yes responses to heart conditions than star conditions ( $p$-values reported in Table 6) - showing that they are more accurate when Froggy's desire is fulfilled. For the mentioned star conditions, we ran the same pairwise comparisons and find a similar pattern. There is no difference in probability of yes responses in the two star conditions or the two heart conditions, but children show a higher pattern of yes responses in the star conditions than the heart conditions ( $p$-values in Table 6) - again, showing that they are somewhat less accurate when there is a conflicting desire.

$\begin{array}{lcc}\text { CONDITION } & \begin{array}{c}\text { Mentioned heart } \\ p \text {-VALUE }\end{array} & \begin{array}{c}\text { Mentioned star } \\ p \text {-VALUE }\end{array} \\ \text { Red heart / Red star } & 0.0002 & 0.0207 \\ \text { Red heart / Yellow heart } & 0.9396 & 0.8786 \\ \text { Red heart / Yellow star } & 0.0012 & 0.0334 \\ \text { Red star / Yellow heart } & 0.0010 & 0.0703 \\ \text { Red star / Yellow star } & 0.7515 & 0.9906 \\ \text { Yellow heart / Yellow star } & 0.0036 & 0.1133\end{array}$

TABLE 6. Pairwise comparisons of probability yes responses across mentioned conditions. For both mentioned heart and mentioned star conditions, we find a significant difference in yes responses for every comparison of heart/star conditions: children are always more likely to give yes responses to mentioned hearts than mentioned stars. In both mentioned heart and mentioned star conditions, for the two heart conditions yes responses were equivalent, and for the two star conditions yes responses were equivalent.

This shows that although children's responses are primarily driven by the mentioned shape, there is also an influence of reality on their responses, although to a much lesser extent. The statistical models that we ran for the want conditions support our conclusion: children are overwhelmingly adult-like in their ability to assess Froggy's desire, responding primarily based on whether heart or star is mentioned in the test item. They are most accurate in heart conditions, the cases where Froggy's desire is fulfilled, although they are always significantly more likely to give yes than no responses whenever hearts are mentioned.

EXPERIMENT 1 SUMMARY. When children are tested under the same experimental conditions for both verbs, four-year-olds are more adult-like in their interpretations of want than think. Children give responses based on reality when interpreting think sentences. When interpreting want sentences, they primarily respond based on desires, although they are most accurate when the desires are not in conflict with reality, showing a lesser effect of reality in the want compared to the think conditions.

3.2. EXPERIMENT 2. Experiment 1 provided a novel demonstration that children's success with desire sentences precedes their success with belief sentences, using a single task that makes both beliefs and desires relevant. This effect was revealed between participants. In experiment 2 , we manipulate verb within participants, so that we can be 
sure that the think/want asymmetry can be observed within the same children. Shifting to a within-subjects design confirms the robustness of children's representations for the meanings of these verbs and their capacity to perform this task. The within-subjects design is very important for experiment 4 , where it is only syntax that changes between blocks, and we needed to first verify that children could, in fact, get multiple different types of interpretations for sentences over the course of this experiment.

SubJECTS. Participants were forty-eight children aged 4;0 to 5;0 (mean $=4 ; 7)$. An additional five children were excluded: two got too many controls wrong, and three did not finish the task. To be included, children needed to complete the experiment and get three of the four controls correct. Children were recruited from the greater Washington, DC, area, through a recruitment database or through local preschools, and tested either in the Project on Children's Language Learning lab at the University of Maryland or at local preschools.

Design AND MATERIALs. The design and materials were very similar to those of experiment 1 (see \$3.1), except that Verb was a within-subjects factor, meaning that each child heard test sentences with both want and think, as in 31 and 32.

(31) Froggy wants it to be/thinks that it's a heart.

(32) Froggy wants it to be/thinks that it's a star.

In a $2 \times 4 \times 2 \times 2$ design, we tested three within-subjects factors: Verb (want vs. think), Condition (red heart, red star, yellow heart, yellow star), and Mentioned shape (heart vs. star). Because each subject heard test sentences with both think and want in a blocked design, we tested Order (1: think first ( $n=24)$ vs. 2: want first $(n=24))$ as a between-subjects factor. The child's response of yes or no was the dependent measure. Just as in experiment 1, on every trial Froggy had both a belief and a desire about the next shape, and each participant encountered every possible combination of realized and nonrealized beliefs or desires. However, because we added an additional withinsubjects factor, we also needed to adjust the number of items in each condition, as simply doubling the number of items would have resulted in a task that was much too long. Given that children's responses on the star items differ across the think and want conditions in experiment 1 , it was critical to have enough star items to determine whether children were changing their interpretation in the second half of the experiment. For this reason, children got more star items in this experiment - six of each (three heart and three star mentioned items per verb). Because the red heart items are controls, children in experiment 2 got only two of each per verb (one heart and one star mention each). We also reduced the number of yellow heart items to two each per verb (one heart and one star mention per verb): because children's responses in experiment 1 showed the same pattern across both verbs for these conditions, they are less informative about children's ability to differentiate think and want than the star conditions. This makes a total of thirty-two test items per child (Table 7). All materials were identical to those described in experiment 1.

$\begin{array}{lllc}\text { CONDITION } & \text { DESIRE } & \text { BELIEF } & \text { \# PER VERB } \\ \text { Red heart } & \text { Fulfilled } & \text { True } & 2 \\ \text { Red star } & \text { Unfulfilled } & \text { False } & 6 \\ \text { Yellow heart } & \text { Fulfilled } & \text { False } & 2 \\ \text { Yellow star } & \text { Unfulfilled } & \text { True } & 6\end{array}$

TABLE 7. Conditions and number of items per condition for experiment 2.

Procedure. The procedure was identical to that described in experiment 1. 
RESUlTS. Children's responses were coded by the second experimenter as the child delivered the response. As in experiment 1, there are three possible response patternsdesire, belief, and reality (Table 2). Adult-like responses are again to respond based on Froggy's desire when the sentence is about what he wants, and based on beliefs when it is about what he thinks. In experiment 1 , children were adult-like in the want conditions, but gave reality-based responses in the think conditions. Assuming that their representations of the verbs are robust and not sensitive to priming effects, we expect the same pattern in experiment 2. Children's responses were measured in proportion of yes responses. We excluded two participants who got fewer than three of the four red heart items correct.

ANALYSIS. Replicating experiment 1, we find that children are adult-like in interpreting want, but influenced by reality with think. Proportion yes responses for all conditions are shown in Table 8 and Figure 4. Bolded responses indicate conditions in which children's responses differed from adult-like responses. Overall, the conditions in which Froggy's mental state conflicted with reality were closer to chance in experiment 2 compared to experiment 1 ; hearing both verbs caused children to be somewhat more susceptible to reality. However, the overall pattern of responses still looks very similar to that in experiment 1 , with children differing from the adult-like pattern in the falsebelief cases (rows 2 and 3, Table 8) more than in the unfulfilled-desire cases (rows 6 and 8 , Table 8).

\begin{tabular}{|c|c|c|c|c|c|}
\hline $\begin{array}{l}\text { VERB } \\
\text { (within subjs) }\end{array}$ & $\begin{array}{c}\text { CONDITION } \\
\text { (within subjs) }\end{array}$ & $\begin{array}{c}\text { MENTAL STATE } \\
\text { STATUS }\end{array}$ & \multirow{2}{*}{$\begin{array}{c}\text { MENTIONED } \\
\text { SHAPE } \\
\text { Heart }\end{array}$} & \multirow{2}{*}{$\begin{array}{l}\text { ADULT-LIKE } \\
\text { RESPONSE } \\
\text { Yes }\end{array}$} & $\begin{array}{c}\text { PROPORTION YES } \\
(S D)\end{array}$ \\
\hline \multirow{8}{*}{ 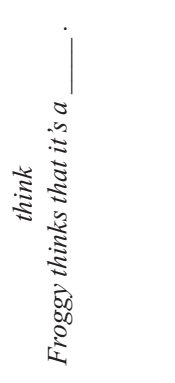 } & \multirow{2}{*}{ 1. Red heart } & \multirow{2}{*}{$\begin{array}{l}\text { True belief, } \\
\text { Fulfilled desire }\end{array}$} & & & $0.98(0.14)$ \\
\hline & & & Star & No & $0.04(0.20)$ \\
\hline & \multirow{2}{*}{ 2. Red star } & \multirow{2}{*}{$\begin{array}{l}\text { False belief, } \\
\text { Unfulfilled desire }\end{array}$} & Heart & Yes & $0.40(0.49)$ \\
\hline & & & Star & No & $0.58(0.50)$ \\
\hline & \multirow{2}{*}{ 3. Yellow heart } & \multirow{2}{*}{$\begin{array}{l}\text { False belief, } \\
\text { Fulfilled desire }\end{array}$} & Heart & No & $0.77(0.42)$ \\
\hline & & & Star & Yes & $0.33(0.48)$ \\
\hline & \multirow{2}{*}{ 4. Yellow star } & \multirow{2}{*}{$\begin{array}{l}\text { True belief, } \\
\text { Unfulfilled desire }\end{array}$} & Heart & No & $0.15(0.36)$ \\
\hline & & & Star & Yes & $0.80(0.40)$ \\
\hline \multirow{8}{*}{ 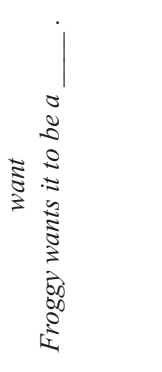 } & \multirow{2}{*}{ 5. Red heart } & \multirow{2}{*}{$\begin{array}{l}\text { True belief, } \\
\text { Fulfilled desire }\end{array}$} & Heart & Yes & $1.00(0.00)$ \\
\hline & & & Star & No & $0.04(0.20)$ \\
\hline & \multirow{2}{*}{ 6. Red star } & \multirow{2}{*}{$\begin{array}{l}\text { False belief, } \\
\text { Unfulfilled desire }\end{array}$} & Heart & Yes & $0.59(0.49)$ \\
\hline & & & Star & No & $0.26(0.44)$ \\
\hline & \multirow{2}{*}{ 7. Yellow heart } & \multirow{2}{*}{$\begin{array}{l}\text { False belief, } \\
\text { Fulfilled desire }\end{array}$} & Heart & Yes & $1.00(0.00)$ \\
\hline & & & Star & No & $0.04(0.20)$ \\
\hline & \multirow{2}{*}{ 8. Yellow star } & \multirow{2}{*}{$\begin{array}{l}\text { True belief, } \\
\text { Unfulfilled desire }\end{array}$} & Heart & Yes & $0.61(0.49)$ \\
\hline & & & Star & No & $0.28(0.45)$ \\
\hline
\end{tabular}

TABLE 8. Proportion yes responses for all conditions in experiment 2. Bolded responses signify conditions in which children's response patterns differed from the predicted adult-like pattern. The patterns differ only in the think conditions where reality differed from the puppet's belief state, again satisfying the predictions shown in Table 2 as well as replicating experiment 1 and previous tasks with think in false-belief situations.

Even in a Verb within-subjects blocked design, children are more adult-like in their responses to want, which match the desire pattern, than in their responses to think, which match the reality pattern. 

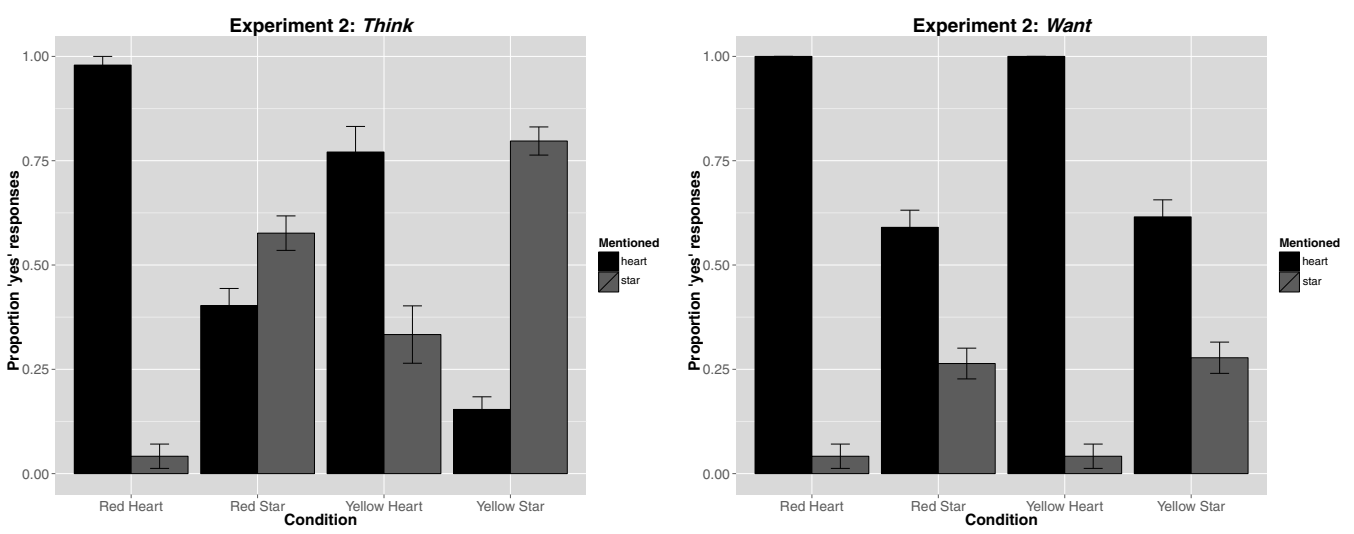

FIGURE 4. Proportion yes responses for all conditions in experiment 2. Desire responses are characterized by yes responses to mentioned heart sentences, which is the pattern observed for want sentences. Reality responses are characterized by yes responses when the mentioned shape matches the actual shape, which is the pattern observed for think sentences.

Statistical analysis of EXPERIMENT 2. We used the same kind of generalized linear mixed-effects models for experiment 2 as for experiment 1 . We first combined data from both orders and performed the same analyses as reported for experiment 1 . We ran a mixed-effect logit model with yes responses as the dependent measure, with Verb, Mentioned, and Condition as fixed effects, and Subject as a random effect. Critically, we find a three-way interaction of Verb, Mentioned, and Condition $\left(\chi^{2}(1)=26.34, p<0.0001\right)$, showing different patterns of responses across each of the verb conditions. As in experiment 1 , we therefore split the data by Verb.

STATISTICAL ANALYSIS OF THINK CONDITIONS. For the think conditions, we conducted the same statistical analyses as described for experiment 1 . We ran a mixed-effect logit model with yes responses as the dependent measure, with Mentioned and Condition as fixed effects, and Subject as a random effect. In this model the two-way interaction between Mentioned and Condition is significant $\left(\chi^{2}(1)=126.90, p<0.0001\right)$, so again we analyzed each level of Condition. We ran four pairwise comparisons over each Condition/Mentioned pair. As in experiment 1, in the heart conditions, children are significantly more likely to say yes to a mentioned heart than to a mentioned star; and in the star conditions, children are significantly more likely to say yes to a mentioned star than to a mentioned heart. Estimated marginal means and $p$-values for each condition are reported in Table 9.

\begin{tabular}{|c|c|c|c|}
\hline CONDITION & PROBABILITY Y & RESPONSE $(S E)$ & $p$-VALUE \\
\hline & Mentioned heart & Mentioned star & \\
\hline Red heart & $0.98(0.02)$ & $0.04(0.03)$ & $<0.0001$ \\
\hline Red star & $0.40(0.04)$ & $0.58(0.05)$ & 0.0034 \\
\hline Yellow heart & $0.78(0.06)$ & $0.33(0.07)$ & $<0.0001$ \\
\hline Yellow star & $0.15(0.03)$ & $0.79(0.03)$ & $<0.0001$ \\
\hline
\end{tabular}

TABle 9. Pairwise comparisons of probability yes responses across think conditions. In heart conditions, children are significantly more likely to give yes responses to mentioned hearts than mentioned stars. In star conditions, children are more likely to give yes responses to mentioned stars than mentioned hearts.

For all conditions, children are more likely to give yes responses when the shape mentioned matches the shape in the condition. In the heart conditions, they are more 
likely to accept mentioned heart sentences than mentioned star sentences. In the star conditions, they are more likely to accept mentioned star sentences than mentioned heart sentences. This effect is somewhat weaker than in experiment 1 (most notably in the red star condition), suggesting that children are overall somewhat less accurate in experiment 2 . This is likely driven by the additional burden of switching between verbs. However, the pattern of responses overall matches experiment 1: children are influenced by reality in their responses to think sentences: they accept the sentence when the mentioned matches the actual shape and reject it when there is a mismatch.

STATistical ANALYSis of WANT CONDITIONS. For the want conditions, we again ran a mixed-effect logit model with yes responses as the dependent measure, with Mentioned and Condition as fixed effects, and Subject as a random effect. In this model we again find a main effect of Mentioned $\left(\chi^{2}(1)=32.78, p<0.0001\right)$, showing that children respond differently when heart is mentioned than when star is mentioned. We also find a significant two-way interaction between Mentioned and Condition $\left(\chi^{2}(1)=39.75\right.$, $p<0.0001$ ). We therefore analyzed further by breaking down each level of Condition. We ran pairwise comparisons over each Condition/Mentioned pair and find that, as in experiment 1 , children are significantly more likely to say yes when heart is mentioned than when star is mentioned for all conditions. Estimated marginal means and $p$-values for each condition are reported in Table 10.

$\begin{array}{lccc}\text { CONDITION } & \begin{array}{c}\text { PROBABILITY YES RESPONSE }(S E) \\ \text { Mentioned heart }\end{array} & p \text {-VALUE } \\ \text { Red heart } & 0.98(0.02) & 0.03(0.03) & <0.0001 \\ \text { Red star } & 0.59(0.05) & 0.25(0.04) & <0.0001 \\ \text { Yellow heart } & 0.98(0.02) & 0.03(0.03) & <0.0001 \\ \text { Yellow star } & 0.62(0.05) & 0.27(0.04) & <0.0001\end{array}$

TABLE 10. Pairwise comparisons of probability yes responses across want conditions. In all conditions, children are significantly more likely to give yes responses to mentioned hearts than mentioned stars.

Our conclusions are again supported - children are overwhelmingly adult-like in their ability to assess Froggy's desires, responding primarily based on whether heart or star is mentioned.

As in experiment 1, the significant interaction between Mentioned and Condition demonstrates that while children are influenced by Froggy's desires when interpreting want sentences, they are not completely adult-like. We thus also ran pairwise comparisons within each of the Mentioned levels. As in experiment 1, when heart is mentioned, children are equally likely to give yes responses across both heart conditions, and equally likely to give yes responses across both star conditions, but they are somewhat more likely to give yes responses to heart conditions than star conditions ( $p$-values reported in Table 11), showing some influence of reality. For the mentioned star conditions we find a similar pattern. There is no difference in probability of yes responses in the two star conditions or the two heart conditions, but children show a higher pattern of yes responses in the star conditions than the heart conditions.

As in experiment 1, although children's responses are primarily driven by the mentioned shape, there is also an influence of reality on their responses: they are most accurate when Froggy's desire is fulfilled. Our conclusions are again supported: children are overwhelmingly adult-like in their ability to assess Froggy's desire, responding primarily based on whether heart or star is mentioned in the test item, with some additional influence of reality. 


$\begin{array}{lcc}\text { CONDITION } & \begin{array}{c}\text { Mentioned heart } \\ p \text {-VALUE }\end{array} & \begin{array}{c}\text { Mentioned star } \\ p \text {-VALUE }\end{array} \\ \text { Red heart / Red star } & 0.0032 & 0.0213 \\ \text { Red heart / Yellow heart } & 1.0000 & 1.0000 \\ \text { Red heart / Yellow star } & 0.0047 & 0.0157 \\ \text { Red star / Yellow heart } & 0.0030 & 0.0213 \\ \text { Red star / Yellow star } & 0.9726 & 0.9931 \\ \text { Yellow heart / Yellow star } & 0.0044 & 0.0157\end{array}$

TABLE 11. Pairwise comparisons of probability yes responses by Mentioned. We find a significant difference in yes responses for every comparison of heart/star conditions: children are always more likely to give yes responses to mentioned hearts than mentioned stars. In both mentioned heart and mentioned star conditions, for the two heart conditions, yes responses were equivalent, and for the two star conditions yes responses were equivalent.

COMPARISON OF ORDERS 1 AND 2. We also ran a model including Order as a fixed effect. Order had no significant interactions with any other factors.

EXPERIMENT 2 SUMMARY. When children hear both think and want in the same experiment, they are adult-like with want and influenced by reality with think. This suggests that the think/want asymmetry is a strong effect, even within individuals. Additionally, it shows that the task demands are not too high for children to switch between interpretations, even when they get multiple sentence conditions in a blocked design. This will become important in experiment 4.

3.3. ExPERIMENTS 1 AND 2 Discussion. Previous literature suggests that there is an asymmetry in children's mastery of think and want. However, those verbs were tested with different methods and experimental contexts. In the experiments presented here, we have controlled for possible experimental differences by testing both verbs in a single experimental context that makes both beliefs and desires relevant, and we find different patterns for four-year-olds' interpretation of think and want. When interpreting think sentences, children respond based on reality. When interpreting want sentences, they are primarily influenced by desires, although we see some influence of reality as well. These findings suggest that in our task, the actual shape is very salient: children are always, to some extent, lured by the mismatch between mentioned and actual shape. How much they are lured by this, however, differs based on the verb condition. These findings are overall consistent with our predictions, and with the previous literature testing think and want; children are categorizing them differently by age four and they are influenced by reality when interpreting think much more than when interpreting want. This pattern holds for both between- and within-subjects comparisons of the verbs.

We can now use the same experimental set-up, which makes salient both beliefs and desires, to test children's interpretation of the unfamiliar attitude verb hope. The patterns in experiments 1 and 2 provide a standard against which 'belief'/'desire' verb interpretations can be assessed. We predict that when hope appears with a nonfinite complement, children will assign it a desire meaning, and their responses will resemble the want conditions. When it appears with a finite complement, however, children will be lured by reality, and their responses will resemble the think conditions.

3.4. EXPERIMENT 3. Even in an identical experimental context, children systematically respond differently to sentences about conflicting desires compared to sentences about conflicting beliefs. We hypothesize that children's ability to categorize attitude verbs differently at such a young age stems from their different syntactic distributions. To test whether children use syntactic environment as a cue to attitude-verb meaning, we test their interpretations of sentences with hope, manipulating syntactic frame. 
SubJects. Participants were forty-eight children aged 4;0 to 5;0 $($ mean $=4 ; 6)$. Four additional children were excluded, two due to getting too many controls incorrect, one due to parental report of the child's exposure to English as less than $80 \%$, and one who did not finish the task. To be included, children needed to complete the experiment and get six of the eight controls correct. Children were recruited from the greater Washington, DC, area, through a recruitment database, and tested in the Project on Children's Language Learning lab at the University of Maryland.

Design AND materials. In a $2 \times 4 \times 2$ design, we manipulated Frame (hope-to vs. hope-that) between subjects and Condition (red heart, red star, yellow heart, yellow star) and Mentioned shape (heart vs. star) within subjects. Experiment 3 used the same game task as experiments 1 and 2 (see $\S 3.1$ ), where both the beliefs and desires of a character are relevant: the context should not independently bias children toward interpretations based on desire, belief, or reality, which will ultimately provide evidence that any differing interpretations stem from the manipulation of the syntax. Differing response patterns across verb in experiments 1 and 2 demonstrate that the context is neutral, and so any difference in interpretations across conditions in experiment 3 must be driven by the syntactic manipulation. As in the previous experiments, on every trial, Froggy has both a DESIRE about shape-because he always wants it to be a heart, and a BELIEF - because when it is red he thinks it is a heart, and when it is yellow he thinks it is a star. The silly puppet, Booboo, utters test sentences about what Froggy hopes, either with a finite complement (33-34) or a nonfinite complement (35-36). The child's job is again is to say whether Booboo is correct or incorrect.

(33) Froggy hopes that it's a heart.

(34) Froggy hopes that it's a star.

(35) Froggy hopes to get a heart.

(36) Froggy hopes to get a star.

All materials were identical to those described in experiment 1.

PRocedure. The procedure here was identical to that of experiment 1.

HyPOTHESES AND PREDICTIONS. This experiment tests whether children are sensitive to syntactic frame in interpreting an unfamiliar attitude verb. If they are, we expect different performances in the hope-to (nonfinite) and hope-that (finite) conditions. Specifically, we expect children to give desire interpretations (like want) with a nonfinite complement, and reality responses (like think) with a finite complement.

If children are not sensitive to syntactic frame in interpreting hope, there are several possible patterns of results we might see. If children already have an adult-like semantic representation for hope, or at least know that in this context it references desires, we expect their responses to pattern with want, irrespective of complement. If children do not know the meaning of hope and guess its meaning through some nonsyntactic strategy, we expect to see chance performance, and no differences between the hope-to and hope-that conditions.

RESULTS. Children's responses were coded by the second experimenter as the child delivered the response. As in experiments 1 and 2, there are three possible response patterns - desire, belief, or reality responses (Table 2). If children know that hope references Froggy's desires, we expect desire-based responses regardless of syntax: children should assent to both 33 and 35. If children do not yet know the meaning of hope and are sensitive to syntax, we expect desire responses in the hope-to condition and reality responses in the hope-that condition: they should assent to 35 regardless of what the 
shape actually is, but to 33 only when the shape actually Is a heart. Children's responses were measured in proportion of yes responses. Just as in experiment 1, red heart items were controls - because this is a true-belief and fulfilled-desire case, we predict the same responses whether the participant responds based on desire, belief, oR reality. We excluded two participants who got fewer than six of the eight red heart items correct.

Analysis. We find that children are more likely to give desire responses (i.e. look adult-like) in the hope-to condition, and to be influenced by reality (i.e. traditional false-belief error) in the hope-that condition. Proportion yes responses are shown in Table 12 and Figure 5. Highlighted responses show conditions in which children's responses differed from adult-like responses (yes to mentioned heart, no to mentioned star). Children differ from the adult-like pattern only in hope-that conditions, and only in cases in which the mentioned does not match reality.

\begin{tabular}{|c|c|c|c|c|c|c|}
\hline $\begin{array}{l}\text { FRAME } \\
\text { (between } \\
\text { subjs) }\end{array}$ & $\begin{array}{l}\text { CONDITION } \\
\text { (within subjs) }\end{array}$ & $\begin{array}{l}\text { MENTAL STATE } \\
\text { STATUS }\end{array}$ & $\begin{array}{l}\text { MENTIONED } \\
\text { SHAPE }\end{array}$ & $\begin{array}{l}\text { PREDICTED } \\
\text { PATTERN }\end{array}$ & $\begin{array}{c}\text { PROPORTION } \\
\text { YES } \\
\text { EXP. } 1\end{array}$ & $\begin{array}{c}\text { PROPORTION } \\
\text { YES } \\
\text { EXP. } 3\end{array}$ \\
\hline \multirow{8}{*}{ 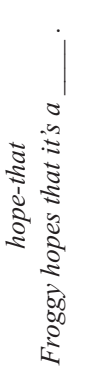 } & \multirow{2}{*}{ 1. Red heart } & \multirow{2}{*}{$\begin{array}{l}\text { True belief, } \\
\text { Fulfilled desire }\end{array}$} & Heart & Yes & $1.00(0.00)$ & $0.95(0.22)$ \\
\hline & & & Star & No & $0.03(0.17)$ & $0.03(0.17)$ \\
\hline & \multirow{2}{*}{ 2. Red star } & \multirow{2}{*}{$\begin{array}{l}\text { False belief, } \\
\text { Unfulfilled desire }\end{array}$} & Heart & No & $0.14(0.35)$ & $0.32(0.47)$ \\
\hline & & & Star & Yes & $0.85(0.40)$ & $0.63(0.49)$ \\
\hline & \multirow{2}{*}{ 3. Yellow heart } & \multirow{2}{*}{$\begin{array}{l}\text { False belief, } \\
\text { Fulfilled desire }\end{array}$} & Heart & Yes & $0.87(0.33)$ & $0.95(0.22)$ \\
\hline & & & Star & No & $0.22(0.41)$ & $0.03(0.17)$ \\
\hline & \multirow{2}{*}{ 4. Yellow star } & \multirow{2}{*}{$\begin{array}{l}\text { True belief, } \\
\text { Unfulfilled desire }\end{array}$} & Heart & No & $0.05(0.21)$ & $0.32(0.47)$ \\
\hline & & & Star & Yes & $0.91(0.31)$ & $0.57(0.50)$ \\
\hline \multirow{8}{*}{ 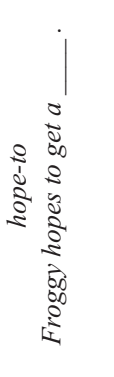 } & \multirow{2}{*}{ 5. Red heart } & \multirow{2}{*}{$\begin{array}{l}\text { True belief, } \\
\text { Fulfilled desire }\end{array}$} & Heart & Yes & $0.98(0.14)$ & $1.00(0.00)$ \\
\hline & & & Star & No & $0.04(0.20)$ & $0.04(0.20)$ \\
\hline & \multirow{2}{*}{ 6. Red star } & \multirow{2}{*}{$\begin{array}{l}\text { False belief, } \\
\text { Unfulfilled desire }\end{array}$} & Heart & Yes & $0.70(0.46)$ & $0.50(0.50)$ \\
\hline & & & Star & No & $0.17(0.37)$ & $0.29(0.46)$ \\
\hline & \multirow{2}{*}{ 7. Yellow heart } & \multirow{2}{*}{$\begin{array}{l}\text { False belief, } \\
\text { Fulfilled desire }\end{array}$} & Heart & Yes & $1.00(0.00)$ & $0.95(0.22)$ \\
\hline & & & Star & No & $0.06(0.24)$ & $0.04(0.20)$ \\
\hline & \multirow{2}{*}{ 8. Yellow star } & \multirow{2}{*}{$\begin{array}{l}\text { True belief, } \\
\text { Unfulfilled desire }\end{array}$} & Heart & Yes & $0.76(0.43)$ & $0.48(0.50)$ \\
\hline & & & Star & No & $0.16(0.36)$ & $0.25(0.44)$ \\
\hline
\end{tabular}

TABLE 12. Proportion yes responses for all conditions in experiment 3. The adult-like pattern for both frame conditions is desire responses (see Table 2, 'desire' column), because in adults, the primary meaning for hope is preferential. However, we expect that children will interpret the sentences differently based on frame, and therefore predict to see reality responses in the hope-that condition, and adult-like desire responses in the hope-to condition ('predicted pattern' column). As predicted, children are more likely to give adult-like desire responses in the hope-to condition, and reality responses in the hope-that condition. For ease of comparison, we have included the results of experiment 1 (think sentences rows 1-4, want sentences rows 5-8). Responses in the hope-that conditions are similar to the think conditions in experiment 1, and responses in the hope-to conditions are similar to the want conditions in experiment 1 . Bolded responses signify the classic 'reality lure' error, which occurs in think conditions of experiment 1 and hope-that conditions of experiment 3 . The red star condition is both false belief and unfulfilled reality, and is therefore the condition in which we can see reality-lure errors for both think and hope-that sentences.

In the hope-to condition, children are adult-like, responding based on desires; in the hope-that conditions, they respond based on reality.

Statistical analysis of EXPERIMENT 3. We used generalized linear mixed-effects models to analyze the results. We first ran a mixed-effect logit model with yes responses 

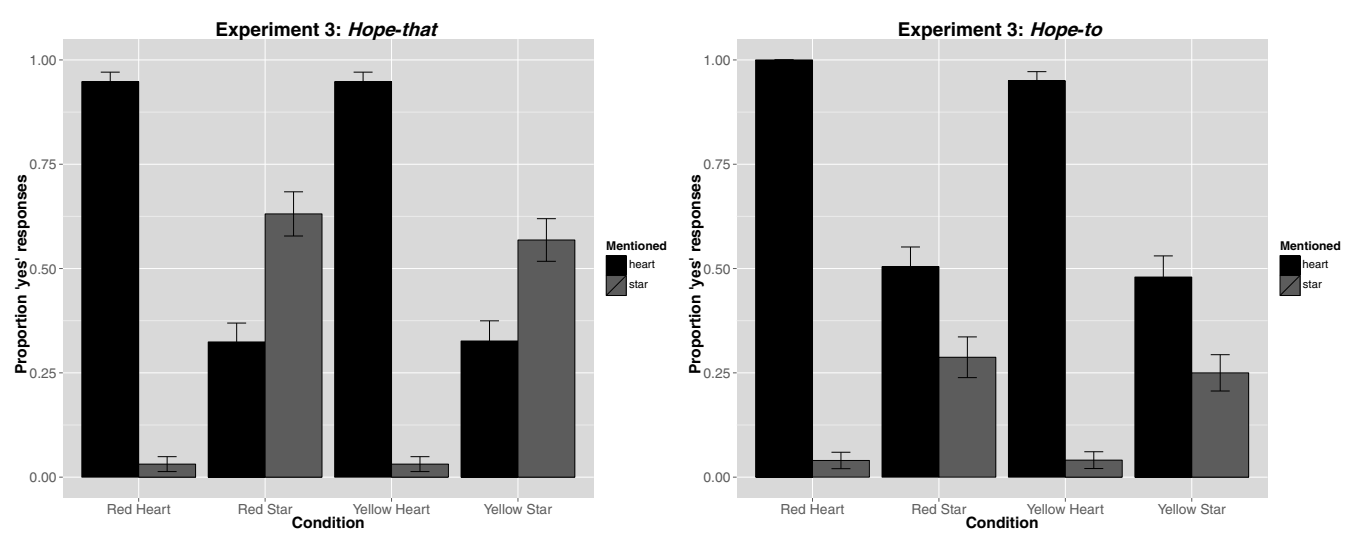

FIGURE 5. Proportion yes responses for all conditions in experiment 3. Desire responses are characterized by more yes responses to mentioned heart sentences, which is the pattern observed for hope-to sentences. Reality responses are characterized by more yes responses when the mentioned shape matches the actual shape, which is the pattern observed for hope-that sentences.

as the dependent measure, with Frame, Mentioned, and Condition as fixed effects, and Subject as a random effect. In this model, we do not find a three-way interaction between Frame, Mentioned, and Condition $\left(\chi^{2}(1)=5.28, p=0.153\right)$. Since the initial model does not show any significant interactions with Frame, we then attempt to remove Frame from the model entirely, by using backward selection by $p$-value through ends to find the best-fit model..$^{5}$ The best-fit model does show a significant two-way interaction between Frame and Mentioned $\left(\chi^{2}(1)=44.86, p<0.0001\right)$, as well as Mentioned and Condition $\left(\chi^{2}(1)=269.89, p<0.0001\right)$, so we split by frame in order to interpret response patterns across conditions.

Statistical anAlysis of HOPE-THAT CONDITIONS. For the hope-that conditions, we again ran a mixed-effect logit model with yes responses as the dependent measure, with Mentioned and Condition as fixed effects, and Subject as a random effect. In this model, the two-way interaction between Mentioned and Condition is again significant $\left(\chi^{2}(1)=169.69, p<0.0001\right)$, so we ran four pairwise comparisons over each Condition/Mentioned pair. In both of the heart conditions, children are more likely to say yes to a mentioned heart than a star. In both of the star conditions, children are more likely to say yes to a mentioned star than a heart. Estimated marginal means and $p$-values for each condition are reported in Table 13.

For all conditions, children are more likely to give yes responses when the shape mentioned matches the shape in the condition. Children are influenced by reality in their responses to hope-that sentences: they assent when the mentioned matches the actual shape, and reject the sentence when mentioned and actual do not match. This matches the observed pattern for think sentences in experiments 1 and 2.

\footnotetext{
${ }^{5}$ Backward selection by $p$-value is a method of variable selection. It is a hierarchical procedure, so it will not remove any main effects if that main effect was involved in an interaction. This procedure first looks to see if the highest-level interaction (in this case three-way) is significant. If it is not, we remove that term from the model, and rerun it at the next level of interactions (two-way). We then repeat this process until no more terms can be removed. This procedure works well here, because it allows us to start with all possible variables in the model, but then appropriately simplify the model to best explain the data. For a further explanation of the process of backward selection by $p$-value, see Kutner et al. 2004.
} 


\begin{tabular}{|c|c|c|c|}
\hline \multirow[t]{2}{*}{ CONDITION } & \multicolumn{2}{|c|}{ PROBABILITY YES RESPONSE (SE) } & \multirow[t]{2}{*}{$p$-VALUE } \\
\hline & Mentioned heart & Mentioned star & \\
\hline Red heart & $0.95(0.02)$ & $0.03(0.02)$ & $<0.0001$ \\
\hline Red star & $0.32(0.05)$ & $0.63(0.05)$ & $<0.0001$ \\
\hline Yellow heart & $0.95(0.02)$ & $0.03(0.02)$ & $<0.0001$ \\
\hline Yellow star & $0.33(0.05)$ & $0.57(0.05)$ & 0.0009 \\
\hline
\end{tabular}

TABLE 13. Pairwise comparisons of probability yes responses across hope-that conditions. In all conditions, children differ significantly in proportion yes responses across mentioned hearts and mentioned stars. In both heart conditions, children are significantly more likely to give yes responses to mentioned hearts than mentioned stars. In star conditions, we see the opposite pattern: children are more likely to give no responses to mentioned hearts than mentioned stars.

STATISTICAL ANALYSIS OF HOPE-TO CONDITIONS. For the hope-to conditions, we ran a mixed-effect logit model with yes responses as the dependent measure, with Mentioned and Condition as fixed effects, and Subject as a random effect. In this model, we find a significant main effect of Mentioned $\left(\chi^{2}(1)=50.00, p<0.0001\right)$, showing that, like for want, children respond differently based on the mentioned shape. We also find a significant two-way interaction between Mentioned and Condition $\left(\chi^{2}(1)=85.55, p<0.0001\right)$, so we analyze each level of Condition. We ran four pairwise comparisons over each Condition/Mentioned pair. We find that for all conditions, children are significantly more likely to say yes when heart is mentioned than when star is mentioned. Estimated marginal means and $p$-values for each condition are reported in Table 14.

\begin{tabular}{|c|c|c|c|}
\hline CONDITION & PROBABILITY $Y$ & ESPONSE $(S E)$ & $p$-VALUE \\
\hline & Mentioned heart & Mentioned star & \\
\hline Red heart & $0.99(0.01)$ & $0.04(0.02)$ & $<0.0001$ \\
\hline Red star & $0.50(0.06)$ & $0.27(0.05)$ & 0.0013 \\
\hline Yellow heart & $0.96(0.02)$ & $0.04(0.02)$ & $<0.0001$ \\
\hline Yellow star & $0.48(0.06)$ & $0.23(0.05)$ & 0.0006 \\
\hline
\end{tabular}

TABLE 14. Pairwise comparisons of probability yes responses across hope-to conditions. In all conditions, children are significantly more likely to give yes responses to mentioned hearts than mentioned stars.

Overall, we see that the pattern here matches most closely the pattern observed for the want conditions in experiments 1 and 2; children are responding primarily based on Froggy's desires. Like in the want conditions for experiments 1 and 2, children are not completely adult-like in giving desire responses, as indicated by the interaction between Mentioned and Condition. For hope-to sentences, we also ran pairwise comparisons within each of the Mentioned levels. When heart is mentioned, children are equally likely to give yes responses across both heart conditions, and equally (un)likely to give yes responses across both star conditions; but they are more likely to give yes responses to heart conditions than star conditions ( $p$-values reported in Table 15) - showing that they are more accurate when there is a fulfilled desire. For the mentioned star conditions, we ran the same pairwise comparisons and find a similar pattern. There is no difference in the probability of yes responses in the two star conditions or the two heart conditions, but children show a higher pattern of yes responses in the star conditions than the heart conditions ( $p$-values in Table 15) - again, although they are still more likely to give yes responses than no responses, demonstrating that while there is some influence of reality on their responses for hope-to sentences, they are more likely to respond based on desire than reality.

This shows that although children's responses are primarily driven by mentioned shape, there is also an influence of reality on their responses. Overall, we see that the pattern here matches most closely the pattern observed for the want conditions in ex- 


$\begin{array}{lcc}\text { CONDITION } & \begin{array}{c}\text { Mentioned heart } \\ p \text {-VALUE }\end{array} & \begin{array}{c}\text { Mentioned star } \\ p \text {-VALUE }\end{array} \\ \text { Red heart / Red star } & <0.0001 & 0.0002 \\ \text { Red heart / Yellow heart } & 0.4379 & 1.0000 \\ \text { Red heart / Yellow star } & <0.0001 & 0.0009 \\ \text { Red star / Yellow heart } & <0.0001 & 0.0003 \\ \text { Red star / Yellow star } & 0.9800 & 0.9434 \\ \text { Yellow heart / Yellow star } & <0.0001 & 0.0011\end{array}$

TABLE 15. Pairwise comparisons of probability yes responses for mentioned conditions. Children are always more likely to give yes responses to mentioned hearts than mentioned stars. In both mentioned heart and mentioned star conditions, for the two heart conditions, yes responses were equivalent, and for the two star conditions, yes responses were equivalent.

periments 1 and 2, although they are influenced more strongly by reality with hope-to than with want.

SUMmARY OF STATISTICAL ANALYSIS FOR EXPERIMENT 3. The main predictor of children's yes responses was different across each of the frame conditions. In the hope-that conditions, children's yes responses are predicted by a match between the mentioned item and actual shape. Children were significantly more likely to give yes responses to mentioned hearts in the heart conditions, and to mentioned stars in the star conditions. These results show the same pattern as observed for think, suggesting that hearing a novel attitude verb with a finite complement triggers reality responses. In the hope-to conditions, children were influenced both by mentioned shape and by a match between mentioned and actual shape, with the strongest predictor being mentioned shape. Although there is a stronger influence of reality here than in experiments 1 and 2, we see the same overall pattern for want and hope-to. These results indicate that four-year-olds are most likely to get a desire interpretation when hearing a novel attitude verb with a nonfinite complement.

EXPERIMENT 3 SUMMARY. Experiment 3 tests children's sensitivity to syntactic frame when interpreting an unfamiliar attitude verb in a context that makes both beliefs and desires salient. Children show different response patterns for hope depending on syntactic frame, suggesting that they use syntax as a cue to attitude-verb meaning. With a nonfinite complement, they are more likely to treat hope as a desire verb; with a finite complement, they make the same reality error as with think. This suggests that at least one of the factors that triggers the traditional false-belief error is the syntax of finite complement clauses, or perhaps more abstractly, declarative syntax in complement clauses.

Although this experiment shows that children are sensitive to syntactic frame in interpreting an attitude verb, it does not yet provide evidence about the amount of syntactic exposure needed to learn an attitude verb and how flexible early representations are. To further explore the learning process, experiment 4 looks at how syntactic distribution influences interpretation throughout the experiment. We investigate this by manipulating syntactic frame within subjects.

3.5. EXPERIMENT 4. In the previous experiment, we saw that children are influenced by syntactic frame when they interpret an unfamiliar attitude verb. However, we do not yet know how they use the frame for longer-term integration into their semantic representation for the verb. Will the meaning they build for hope in the experiment have a lasting influence when the syntactic context changes? Evidence from studies on syntactic bootstrapping and syntactic priming suggest that children can carry word-meaning information gleaned from syntactic context forward to later experiences with words (Naigles 1996, Scott \& Fisher 2009, among others). Experiment 4 explores how this 
works for attitude-verb learning: are a few experiences with an attitude verb enough for children to influence their future interpretations of the verb? Or is more experience required, and do their representations remain flexible and susceptible to changes in the syntactic frame?

Experiment 4 investigates the question of how children use syntactic frame, and how flexible they are in the meaning they attribute based on frame (cf. Naigles et al. 1993). As in experiment 3 , we give children sentences with hope in a context that makes both beliefs and desires salient. This time, however, we give children sentences with hope with both finite and nonfinite complements. Do children treat each trial as an individual case, or do they integrate information from previous trials into their semantic representation?

SubJects. Participants were forty-seven children aged $4 ; 0$ to $5 ; 0$ (mean $=4 ; 6)$. Four additional children were excluded, two due to getting too many controls incorrect and two who did not finish the task. To be included, children needed to complete the experiment and get three of the four controls correct. Children were recruited from the greater Washington, DC, area, through a recruitment database or through local preschools, and tested either in the Project on Children's Language Learning lab at the University of Maryland or at local preschools.

DESIGN AND MATERIALs. Experiment 4 was the same game task used in experiment 2 (see §3.2), except that instead of manipulating Verb (want/think) within subjects, we manipulated Frame for hope in a blocked design. Children heard all of the test sentences (37-40) over the course of the experiment.

(37) Froggy hopes that it's a heart.

(38) Froggy hopes that it's a star.

(39) Froggy hopes to get a heart.

(40) Froggy hopes to get a star.

In a $2 \times 4 \times 2 \times 2$ design, we tested three within-subjects factors: Frame (hope-that vs. hope-to), Condition (red heart, red star, yellow heart, yellow star), and Mentioned shape (heart vs. star). Because each subject heard both hope-that and hope-to sentences in a blocked design, we tested Order (1: hope-that first $(n=24)$ vs. 2: hope-to first $(n=23))$ as a between-subjects factor. The child's response of yes or no was the dependent measure. As in experiments 1-3, on every trial Froggy had both a belief and a desire about the next shape, and participants encountered every possible combination of true and false beliefs, and fulfilled and unfulfilled desires. The distribution of items across Condition was identical to that of experiment 2 (Table 7).

All materials were identical to those described in experiment 2.

Procedure. The procedure here was identical to that of experiment 2.

HypotheSES AND PREDICTIONS. Experiment 3 showed that children are sensitive to syntactic frame in interpreting an unfamiliar attitude verb. In this experiment, we probe how the semantic representation is built up over multiple exposures. If children immediately integrate information gleaned from syntactic frame, we expect that their performance will change in the second block of this task.

REsults. Children's responses were coded by the second experimenter as the child delivered the response. As in all previous experiments reported here, there are three possible response patterns: desire, belief, or reality responses (Table 2). In experiment 3 , children were more likely to give desire responses with hope-to, and reality responses with hope-that. In this experiment, we expect to see the same pattern emerge in the first block. In the second block, however, there are two possible outcomes. One is 
that children's interpretations of hope are always driven by the current syntax in which it is presented: children should interpret hope-that identically regardless of block. The second possibility is that children use their experiences with hope in the first half to hypothesize something about its meaning. If so, we expect children's responses in the second half to be influenced by the frame they heard in the first half.

Children's responses were measured in proportion of yes responses. We excluded two participants who got fewer than three of the four red heart items correct.

ANALYSIS. Because we are interested in the effect that the first block has on the second block, we present data for each block separately (Table 16, Figures 6 and 7). Looking only at the first blocks-hope-that in order 1 and hope-to in order 2 (italicized in Table 16), we replicate experiment 3. Children are more likely to give desire responses in the hope-to condition and to be influenced by reality in the hope-that condition. These reality-lure errors are indicated with bold text in Table 16. In the second blocks (nonitalicized data below), we see a different pattern. When the children in order 1 interpret sentences with hope-to after hearing hope-that first, the pattern of their responses no longer fits either a desire or a belief response. On the conditions in which desire and reality predict different response patterns (both star conditions), children's responses pattern with neither response type strongly. While they are influenced by the finite frame in the first half, this influence is not enough to completely override the nonfinite frame they hear in the second half. They are influenced by both the frame heard in the first half AND the frame heard in the second half. This pattern is especially evident in the star conditions of the graphs in Fig. 6.

The participants in order 2 hear hope-to first and then hope-that. In this condition we also see that the first block influences responses in the second block. In this case, however, responses in all conditions look similar to the responses in the first block. This is particularly evident in the star conditions of the graphs in Fig. 7. Children are influenced by the syntactic frames heard in the first half of the experiment. However, the AMOUNT of influence seems to vary with the particular order of frames: when children hear a nonfinite complement first, this experience seems to override the influence of the finite complement at a later point. When they hear a finite complement first they are less influenced.

As shown above, data in the first blocks of each order replicates findings from experiment 3 . In the second blocks, children are influenced by syntactic frames that they heard earlier in the study, sometimes even enough to override the syntax of the current sentence.

StATISTICAL ANALYSIS OF EXPERIMENT 4. We split by Order and block to determine how the response patterns across each block match the patterns in experiment 3. For each order, we analyze the first block to ensure replication of experiment 3 . Then we analyze the second block to determine whether the response pattern matches conditions of the current frame or the previous frame.

Statistical analysis of order 1, block 1. In the first block of order 1, children heard hope-that sentences. As in experiment 3, we ran a mixed-effect logit model with yes responses as the dependent measure, with Mentioned and Condition as fixed effects, and Subject as a random effect. In this model, again the two-way interaction between Mentioned and Condition is significant $\left(\chi^{2}(1)=70.72, p<0.0001\right)$, so we ran four pairwise comparisons over each Condition/Mentioned pair. In the heart conditions, children are more likely to say yes to a mentioned heart than to a mentioned star. In the star conditions, children are more likely to say yes to a mentioned star than to a mentioned heart. Estimated marginal means and $p$-values for each condition are reported in Table 17. 


\begin{tabular}{|c|c|c|c|c|c|}
\hline $\begin{array}{l}\text { ORDER } \\
\text { (between } \\
\text { subjs) }\end{array}$ & $\begin{array}{c}\text { CONDITION } \\
\text { (within subjs) }\end{array}$ & $\begin{array}{l}\text { MENTIONED } \\
\text { SHAPE }\end{array}$ & $\begin{array}{l}\text { PREDICTED } \\
\text { RESPONSE }\end{array}$ & $\begin{array}{c}\text { ORDER } 1 \\
\text { (hope-that } 1 \mathrm{st}) \\
\text { PROPORTION } \\
\text { YES }(S D)\end{array}$ & $\begin{array}{c}\text { ORDER } 2 \\
\text { (hope-to } 1 \mathrm{st}) \\
\text { PROPORTION } \\
\text { YES }(S D)\end{array}$ \\
\hline \multirow{8}{*}{ 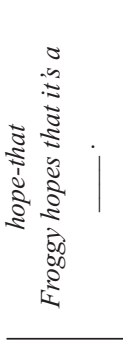 } & \multirow{2}{*}{ 1. Red heart } & Heart & Yes & $1.00(0.00)$ & $0.96(0.20)$ \\
\hline & & Star & No & $0.00(0.00)$ & $0.17(0.38)$ \\
\hline & \multirow{2}{*}{ 2. Red star } & Heart & No & $0.23(0.42)$ & $0.50(0.50)$ \\
\hline & & Star & Yes & $0.58(0.50)$ & $0.11(0.32)$ \\
\hline & \multirow{2}{*}{ 3. Yellow heart } & Heart & Yes & $0.92(0.28)$ & $1.00(0.00)$ \\
\hline & & Star & No & $0.12(0.33)$ & $0.08(0.28)$ \\
\hline & \multirow{2}{*}{ 4. Yellow star } & Heart & No & $0.12(0.33)$ & $0.47(0.50)$ \\
\hline & & Star & Yes & $0.58(0.50)$ & $0.14(0.35)$ \\
\hline \multirow{8}{*}{ 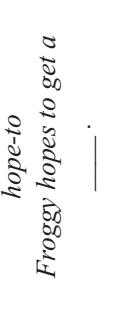 } & \multirow{2}{*}{ 5. Red heart } & Heart & Yes & $0.96(0.20)$ & $0.96(0.20)$ \\
\hline & & Star & No & $0.08(0.28)$ & $0.08(0.28)$ \\
\hline & \multirow{2}{*}{ 6. Red star } & Heart & Yes & $0.35(0.48)$ & $0.52(0.50)$ \\
\hline & & Star & No & $0.37(0.49)$ & $0.26(0.45)$ \\
\hline & \multirow{2}{*}{ 7. Yellow heart } & Heart & Yes & $0.92(0.28)$ & $0.95(0.20)$ \\
\hline & & Star & No & $0.20(0.41)$ & $0.13(0.34)$ \\
\hline & \multirow{2}{*}{ 8. Yellow star } & Heart & Yes & $0.26(0.45)$ & $0.50(0.50)$ \\
\hline & & Star & No & $0.37(0.49)$ & $0.26(0.44)$ \\
\hline
\end{tabular}

TABLE 16. Proportion yes responses for all conditions in experiment 4. Italicized responses indicate first blocks in each order, which replicate findings from experiment 3. When children hear hope-that, they give the classic reality responses when asked about a conflicting mental state (indicated with bold text); when they hear hope-to they give desire responses. In the second halves, we see differential influence of the frame from the first halves: in order 1 , children do not continue to follow the reality pattern, but in order 2 , children continue to give desire responses, even after the syntax is no longer suggestive of the desire subclass.
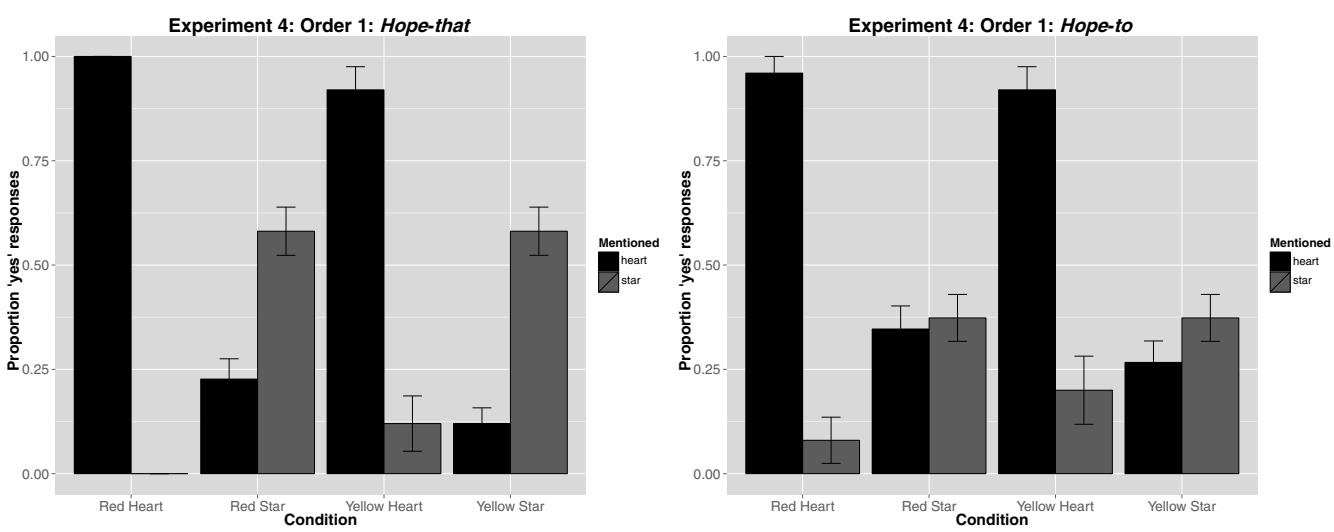

FIGURE 6. Proportion yes responses for order 1 of experiment 4. Participants heard hope-that sentences first and show the signature reality response: higher proportion yes responses when the mentioned shape matches the actual shape. In the second half, when children heard hope-to, the pattern disappears, suggesting that they are not maintaining their reality interpretation when the syntax changes in the second half.

Replicating experiment 3, children are influenced by reality. They are more likely to give yes responses when the shape mentioned matches the shape in the condition.

Statistical analysis of order 1 , block 2 . In the second block of order 1 , children heard hope-to sentences. We ran a mixed-effect logit model with yes responses as the dependent measure, with Mentioned and Condition as fixed effects, and Subject as a random effect. In this model, the two-way interaction between Mentioned and Condi- 

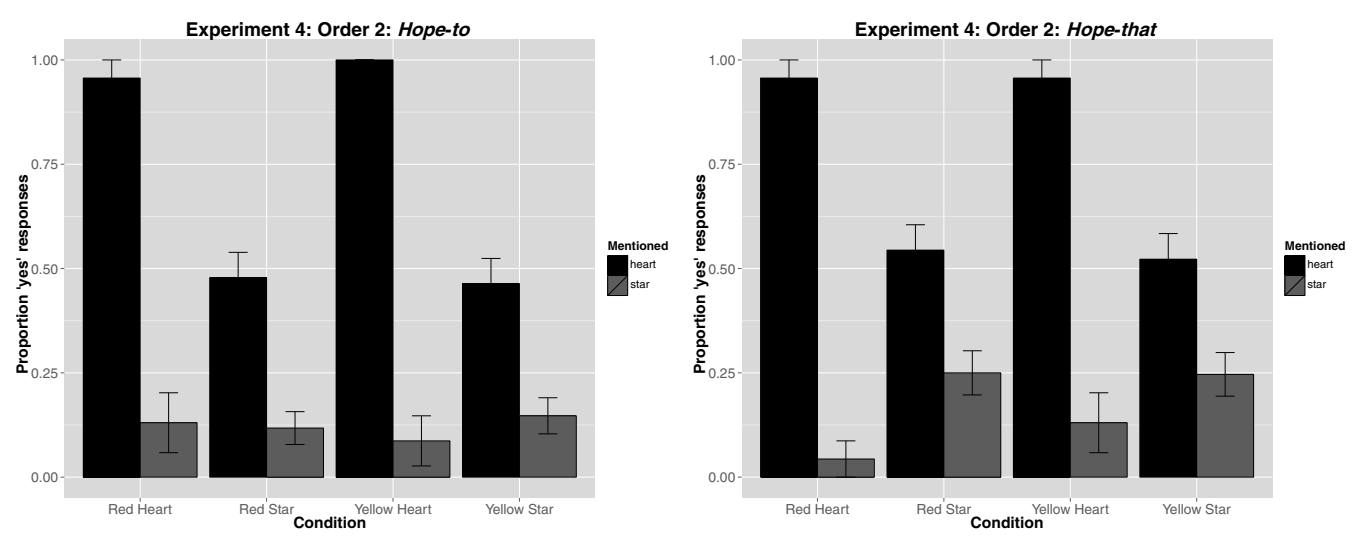

FIGURE 7. Proportion yes responses for order 2 of experiment 4. Participants heard hope-to sentences first and show the signature desire response: higher proportion yes responses for mentioned heart sentences.

In the second half, when children heard hope-that, they maintain the desire pattern.

\begin{tabular}{|c|c|c|c|}
\hline \multirow[t]{2}{*}{ CONDITION } & \multicolumn{2}{|c|}{ PROBABILITY YES RESPONSE (SE) } & \multirow[t]{2}{*}{$p$-VALUE } \\
\hline & Mentioned heart & Mentioned star & \\
\hline Red heart & $0.97(0.03)$ & $0.03(0.03)$ & $<0.0001$ \\
\hline Red star & $0.20(0.05)$ & $0.59(0.07)$ & $<0.0001$ \\
\hline Yellow heart & $0.93(0.05)$ & $0.10(0.06)$ & $<0.0001$ \\
\hline Yellow star & $0.10(0.04)$ & $0.59(0.07)$ & 0.0009 \\
\hline
\end{tabular}

TABLE 17. Pairwise comparisons of probability yes responses across hope-that conditions. In all conditions, children give significantly different proportions of yes responses across mentioned hearts and mentioned stars. In both heart conditions, children are more likely to give yes responses to mentioned hearts than stars.

In the star conditions, children are more likely to give yes responses to mentioned stars than hearts.

tion is significant $\left(\chi^{2}(1)=40.19, p<0.0001\right)$, so we ran four pairwise comparisons over each Condition/Mentioned pair. This reveals a different pattern than we have seen in any of the previous studies - it does not match the desire or the reality patterns. In the heart conditions, children are more likely to say yes to mentioned hearts than to mentioned stars, consistent with either a desire or reality interpretation. In the star conditions, however, they are not more likely to say yes to either mentioned hearts or mentioned stars. Estimated marginal means and $p$-values for each condition are reported in Table 18.

\begin{tabular}{|c|c|c|c|}
\hline \multirow[t]{2}{*}{ CONDITION } & \multicolumn{2}{|c|}{ PROBABILITY YES RESPONSE (SE) } & \multirow[t]{2}{*}{$p$-VALUE } \\
\hline & Mentioned heart & Mentioned star & \\
\hline Red heart & $0.96(0.04)$ & $0.08(0.05)$ & $<0.0001$ \\
\hline Red star & $0.34(0.06)$ & $0.37(0.06)$ & 0.7300 \\
\hline Yellow heart & $0.92(0.05)$ & $0.19(0.08)$ & $<0.0001$ \\
\hline Yellow star & $0.26(0.05)$ & $0.37(0.06)$ & 0.1574 \\
\hline
\end{tabular}

TABLE 18. Pairwise comparisons of probability yes responses across hope-to conditions. Children are more likely to give yes responses to mentioned hearts in heart conditions, but are equally likely to give yes responses to either mentioned shape in star conditions.

This supports our conclusion that after hearing sentences with hope-that, children's interpretation of sentences with hope-to is affected. They are influenced both by the current frame and by the earlier frame.

Statistical analysis of order 2, block 1 . In the first block of order 2, children heard hope-to sentences. As in experiment 3, we ran a mixed-effect logit model with yes re- 
sponses as the dependent measure, with Mentioned and Condition as fixed effects, and Subject as a random effect. In this model, the two-way interaction between Mentioned and Condition is significant $\left(\chi^{2}(1)=16.53, p<0.0001\right)$, so we ran four pairwise comparisons over each Condition/Mentioned pair. In all conditions, children are significantly more likely to say yes to a mentioned heart than to a mentioned star. Estimated marginal means and $p$-values for each condition are reported in Table 19.

$\begin{array}{lccc}\text { CONDITION } & \begin{array}{c}\text { PROBABILITY YES RESPONSE }(S E) \\ \text { Mentioned heart }\end{array} & p \text {-VALUE } \\ \text { Red heart } & 0.97(0.03) & 0.10(0.06) & <0.0001 \\ \text { Red star } & 0.47(0.08) & 0.09(0.04) & <0.0001 \\ \text { Yellow heart } & 0.97(0.03) & 0.06(0.05) & <0.0001 \\ \text { Yellow star } & 0.45(0.08) & 0.11(0.04) & <0.0001\end{array}$

TABLE 19. Pairwise comparisons of probability yes responses across hope-to conditions. In all conditions, children are more likely to give yes responses to mentioned hearts than mentioned stars.

Replicating experiment 3, children are more likely to give yes responses to mentioned hearts than to mentioned stars in all conditions.

Statistical analysis of order 2, block 2 . In the second block of order 2, children heard hope-that sentences. We ran a mixed-effect logit model with yes responses as the dependent measure, with Mentioned and Condition as fixed effects, and Subject as a random effect. In this model, the two-way interaction between Mentioned and Condition is significant $\left(\chi^{2}(1)=21.38, p<0.0001\right)$, so we ran four pairwise comparisons over each Condition/Mentioned pair. In all conditions, children are significantly more likely to say yes to a mentioned heart than to a mentioned star. Estimated marginal means and $p$-values for each condition are reported in Table 20.

\begin{tabular}{|c|c|c|c|}
\hline CONDITION & PROBABILITY Y & RESPONSE $(S E)$ & $p$-VALUE \\
\hline & Mentioned heart & Mentioned star & \\
\hline Red heart & $0.97(0.04)$ & $0.04(0.04)$ & $<0.0001$ \\
\hline Red star & $0.54(0.07)$ & $0.23(0.06)$ & 0.0003 \\
\hline Yellow heart & $0.97(0.04)$ & $0.11(0.07)$ & $<0.0001$ \\
\hline Yellow star & $0.52(0.07)$ & $0.22(0.06)$ & 0.0007 \\
\hline
\end{tabular}

TABLE 20. Pairwise comparisons of probability yes responses across hope-that conditions. In all conditions, children are more likely to give yes responses to mentioned hearts than mentioned stars, showing the same pattern as observed in the first block (hope-to).

This suggests that children have used the syntactic frame in the first block to hypothesize something about hope's meaning. After hearing hope-to first, children continue to interpret hope-that sentences consistent with desire interpretations, giving more yes responses to mentioned hearts than to mentioned stars across all conditions.

EXPERIMENT 4 SUMMARY AND DISCUSSION. In experiment 4, we explored children's sensitivity to syntactic frame for attitude-verb learning. We find that, as in experiment 3 , children use syntactic frame as a cue to meaning. Additionally, we find that children integrate this information across multiple trials. When the frame changed in the second half of the experiment, children did not reliably change their interpretation; rather, they seemed to integrate information from their previous experience with the verb. In the first blocks of each order in experiment 4, we replicate findings from experiment 3 , showing that children are more likely to give desire-based responses with a nonfinite complement, and reality-based responses with a finite complement. In the second blocks of both orders, we see evidence of earlier trials influencing later trials, supporting the view that children build a meaning based on exposures in multiple frames. We 
know from the results in experiment 2 that children are not always influenced by the first block in this experimental set-up. In experiment 2, children gave reality responses for think and primarily desire responses for want, regardless of the order of presentation. The fact that we do not see priming effects for want and think is informative about how to interpret the results here. First, it confirms that children had likely not yet solidified a semantic representation for hope before participating in our experiment. It also suggests that the effect is not driven by a lower-level priming within the context of the task (children simply getting into the habit of giving reality or desire responses and continuing this without really listening to the sentence), but may really be about children hypothesizing a meaning for hope based on the syntactic frame of the first block.

We also observe that children do not weigh all syntactic information equally. In order 1, children hear hope-that first and assign a belief interpretation; in the second block they hear hope-to and at least to some extent disregard the belief interpretation in favor of a desire interpretation. When children hear hope-to in the first block of order 1, they assign a desire interpretation. When they hear hope-that in the second block, they maintain their desire interpretation, despite the change in syntactic frame. This asymmetrical influence suggests that the nonfinite frame may be a more informative learning cue about the meaning of the verb than the finite frame.

Possible CAuses of ASYMmetrical influence of SyntaCtic FRAME. There are multiple possible causes of the asymmetrical results of experiment 4 . One is that this effect is driven by an input effect for the verb hope. We analyzed instances of hope in the Gleason corpus of the CHILDES database (Gleason 1980, MacWhinney 2000). This corpus contains dinnertime conversation transcripts from the families of twenty-four children aged 2;1 to 5;2. The entire corpus contains nineteen uses of hope in 36,901 total utterances. All uses of hope were from adults. Of these hope utterances, two were 'I hope not', one was 'I hope so', and two used hope as a noun. Fourteen utterances used hope with a sentential complement. Of these, thirteen had a finite complement and only one a nonfinite complement, suggesting that children are more likely to have been exposed to hope with a finite complement. So, children's prior experience with hope, while limited, may be influencing their performance in our task. Because the finite complement is more common in the input, the nonfinite complement may be more salient to the learner, and therefore have stronger effects in our task.

A second possible explanation for the asymmetry also relies on prior input for hope: it could be that prior experience with hope is enough for children to have a partial lexical representation of the adult-like desire meaning for hope. This partial lexical representation may make children more sensitive to nonfinite complements, because it aligns with their lexical representation and reinforces their hypothesis. Hence, children may weigh nonfinite complements more heavily than finite ones, regardless of order of presentation.

A third possibility is that the observed asymmetry is a methodological artifact. Across all of the experiments, in the want and hope-to conditions children respond primarily based on the puppet's desires, with more yes responses to mentioned hearts and more no responses to mentioned stars. In each of the experiments, however, we also see a smaller but consistent effect of reality. It appears that the design of the task makes reality salient enough that children are less accurate even in the want conditions when there is a conflict. Hearing hope-that first may make the reality conflicts even more salient, enough to cause children hearing hope-to in the second block to be lured by reality more often than children hearing hope-to alone. It is important to note, however, that the salience of reality is not enough to override a desire interpretation for want in the second block of order 
1 of experiment 2, suggesting that children are more vulnerable to the influence of reality when interpreting a verb with which they have less experience.

A final possibility is a deeper linguistic connection between non-main-clause syntax and the preferential subclass of attitude verbs. In this case, the nonfinite frame may be a more straightforward cue to the meaning of the embedding verb. Prior crosslinguistic work suggests that at the right level of abstraction, there is a trackable pattern between syntactic distribution and semantic class for attitude verbs (Hacquard 2014, Hacquard $\&$ Lidz 2019). Future work may be informative about which aspects of this relation are the most crosslinguistically robust, and therefore possible candidates for innateness. Our results are compatible with each of these possibilities, and we leave adjudicating among them for future research.

3.6. EXPERIMENTS 3 AND 4 DISCUSSION. Experiments 3 and 4 addressed children's sensitivity to syntactic frame in interpreting attitude verbs, and how information from syntax carries over future encounters of the same verb in a different frame. We have done this by looking at children's interpretation of hope sentences with a nonfinite complement, which is typically associated with desire verbs, and with a finite complement, which is typically associated with belief verbs.

We have shown that children are sensitive to syntactic frame, suggesting that they use syntax as a cue for interpretation: when children hear a verb with a nonfinite complement, they tend to treat it as if it expresses desires; when they hear it with a finite complement, they make the same reality-lure error as with think. We have also shown that children integrate syntactic information across multiple trials, and that, at least for hope, the finite frame functions as a weaker cue than the nonfinite one.

3.7. Remaining QUestions AND FUTURe DiRections. In this section, we briefly summarize some questions left unanswered and point to some future directions. We are planning a series of follow-up experiments using a similar design, but with a truly novel verb to address some of these issues, and to control for the role of prior experience with hope in our results.

One remaining question is whether the syntactic bootstrapping effects we observed in experiments 3 and 4 were driven by surface differences between the two hope frames. We argue that children are sensitive to the difference between finite and nonfinite complements, and their early differentiation of think and want lend some support to this hypothesis. However, the frame used in the hope-to condition did not contain an explicit subject in the embedded clause, in contrast to the finite frames throughout all experiments and the nonfinite want frame in experiments 1 and 2. This lack of subject could have had an effect on interpretation: perhaps children were interpreting the hopeto sentences as referencing Froggy's desires more generally, and not specifically the shape at hand. The novel verb study will allow us to control for this issue, as we will use a nonfinite complement identical to the want frames in experiments 1 and 2 (Froggy gorps it to be a heart).

The results of experiment 4 show an asymmetry in the influence of finite and nonfinite complements. There are several possibilities for what might be behind these asymmetries, including input effects, partial lexical knowledge for hope, or perhaps a deeper, universal relation between desire semantics and nonfinite syntax. Our novel-verb study will also help us better understand this asymmetry. If it is driven by input effects for hope, it should disappear with a novel verb. If it is driven by a deeper relation between nondeclarative main-clause syntax and desire meanings, the asymmetry should persist.

Another issue is whether children actually infer something about the lexical semantics of hope from the syntactic frame, or merely assume indirect assertions with a finite 
frame and respond accordingly. ${ }^{6}$ While we cannot rule this option out, a few pieces of evidence suggest that children are truly learning something about the meaning of the verb itself. The first is that in experiment 4, children carried over information about the verb from the first block into the second block, especially when they heard hope-to first. If they were just responding to the perceived illocutionary force of the utterance at hand, we would not expect to see such effects. The second piece of evidence comes from findings by Lewis et al. (2017) (discussed in §2). This work suggests that children know something about the meaning of think by age three: in the right contexts, children are able to successfully reject literally false sentences, even when the complement is true. This suggests that they have access to the literal, belief-ascription meaning of think and that their errors are essentially pragmatic. In our experiment, we failed to replicate this pattern: children tended to respond to the truth of the complement, even when the think sentence was false. There are several critical differences between the two sets of studies: in Lewis et al.'s hide-and-seek task, the original question under discussion is that of the hider's location, driving indirect-assertion interpretations. When the second seeker is introduced, however, another question becomes important in the task: that of who will win, and to answer this question, the beliefs of the seekers become very relevant and thus more salient. In our experiments, only Froggy's beliefs are relevant. Although we alert the child to the relevance of his beliefs during the 'belief check', once the game has started, it seems that the most relevant question is whether Froggy will get a sticker on each trial, and thus the shape's identity. The high salience of reality in our task is also evident in the want conditions of experiments 1 and 2, where the lure of reality in our task is strong enough to cause some reality errors, although it is well established that children are adult-like in their interpretation of want by age 3.

Finally, there are questions about the boundaries of the syntactic bootstrapping mechanism that remain unanswered and will influence our future work. One such open question is that of the full range of syntax-semantics links to which the learner is sensitive. We have started with finiteness, as this is reliable in English for differentiating verbs with which children have a significant amount of early experience, but there is still much to be explored in terms of the syntactic features children can utilize for attitudeverb learning and how far these syntactic features will go toward their learning semantic representations for a full range of attitudes. This work also leaves open questions about the source of children's knowledge of these connections. The crosslinguistic facts discussed in $\$ 2$ suggest that the link between embedded main-clause syntax and the representational class of attitude verbs may be innate (for evidence that such a link could be exploited in attitude learning even in a morphosyntactically poor language like Mandarin, see Huang et al. 2018).

4. Conclusions. Attitude verbs express psychological states whose contents are not directly observable. To learn their meanings, children may thus rely on linguistic context, specifically the syntactic frames in which they occur, as evidence about their meanings. Our studies show that children use features of the sentential complement when interpreting an unfamiliar attitude verb. In a series of experiments that make beliefs and desires salient, we have tested children's interpretation of the verbs think, want, and hope. We reproduce the long-noted asymmetry in children's interpretation of think vs. want: children are adult-like in their responses to want, but are lured by reality in their responses to think. We further show that children's responses to the unfamiliar verb hope are highly influenced by the syntactic frame in which it appears: with a non-

${ }^{6}$ We thank a referee for helpful discussion on this point. 
finite complement, children's responses resemble desire responses; with a finite complement, they resemble their responses to think, showing classic reality-based errors.

Although many studies have demonstrated children's ability to use syntactic information for word learning, our experiments explore children's sensitivity to a syntaxsemantics connection not previously reported. While the foundational work in syntactic bootstrapping emphasized the utility of syntactic cues in acquiring mental-state verbs (Landau \& Gleitman 1985, Gleitman 1990, Gillette et al. 1999), work examining children's use of syntax in verb learning has primarily focused on action verbs (for review, see Fisher et al. 2019). In this body of work, the emphasis has been on the number and position of syntactic arguments, but not their syntactic category. Here, we have shown that children are sensitive to the subtypes of clausal arguments in drawing inferences about the meanings of unfamiliar attitude verbs. This work thus makes good on the promise that syntactic features are an important source of evidence about verbs whose relation to events in the physical world is obscure.

\section{REFERENCES}

Agresti, Alan. 2002. Categorical data analysis. 2nd edn. New York: Wiley.

Anand, Pranav, and Valentine Hacquard. 2013. Epistemics and attitudes. Semantics and Pragmatics 6:8. DOI: 10.3765/sp.6.8.

BaAyen, R. Harald. 2008. Analyzing linguistic data: A practical introduction to statistics using $R$. Cambridge: Cambridge University Press.

BALDWIN, DARE A. 1991. Infants' contribution to the achievement of joint reference. Child Development 62(5).875-90. DOI: 10.1111/j.1467-8624.1991.tb01577.x.

Bartsch, Karen, and Henry M. Wellman. 1995. Children talk about the mind. New York: Oxford University Press.

Becker, Misha, and Bruno Estigarribia. 2013. Harder words: Learning abstract verbs with opaque syntax. Language Learning and Development 9(3).211-44. DOI: 10.1080 /15475441.2013.753798.

Bloom, Paul. 2000. How children learn the meaning of words. Cambridge, MA: MIT Press.

Bolinger, Dwight. 1968. Aspects of language. New York: Harcourt, Brace \& World.

Buttelmann, David; Malinda Carpenter; and Michael Tomasello. 2009. Eighteenmonth-old infants show false belief understanding in an active helping paradigm. Cognition 112(2).337-42. DOI: 10.1016/j.cognition.2009.05.006.

Clark, Eve V. 1990. Speaker perspective in language acquisition. Linguistics 28(6).120120. DOI: 10.1515/ling.1990.28.6.1201.

DE ViLliers, JiLl G. 1995. Steps in the mastery of sentence complements. Paper presented at the biennial meeting of the Society for Research in Child Development, Indianapolis, March.

DE Villiers, JiLl G. 2005. Can language acquisition give children a point of view? Why language matters for theory of mind, ed. by Janet Wilde Astington and Jodie A. Baird, 186-219. New York: Oxford University Press. DOI: 10.1093/acprof:oso/9780195159 912.003.0010.

DE VILLIERS, JILL G. 2007. The interface of language and theory of mind. Lingua 117.185878. DOI: 10.1016/j.lingua.2006.11.006.

de Villiers, Jill G., and Peter A. De Villiers. 2000. Linguistic determinism and the understanding of false beliefs. Children's reasoning and the mind, ed. by Peter Mitchell and Kevin Riggs, 191-228. Hove: Psychology Press.

De Villiers, Jill G., and Peter A. De ViLliers. 2009. Complements enable representation of the contents of false belief: The evolution of a theory of theory of mind. Language acquisition, ed. by Susan Foster-Cohen, 169-95. London: Palgrave Macmillan. DOI: $10.1057 / 97802302407808$.

De Villiers, JiLl G., and JenNie E. Pyers. 2002. Complements to cognition: A longitudinal study of the relationship between complex syntax and false-belief-understanding. Cognitive Development 17(1).1037-60. DOI: 10.1016/S0885-2014(02)00073-4. 
Diesendruck, GiL, and LORI Markson. 2001. Children's avoidance of lexical overlap: A pragmatic account. Developmental Psychology 37(5).630-41. DOI: 10.1037/0012 $-1649.37 .5 .630$.

FARKAS, DonKa. 1985. Intensional descriptions and the Romance subjunctive mood. New York: Garland.

Fisher, Cynthia H.; Yael Gertner; Rose M. Scott; and Sylvia Yuan. 2010. Syntactic bootstrapping. Wiley Interdisciplinary Reviews: Cognitive Science 1(2).143-49. DOI: 10.1002/wcs.17.

Fisher, Cynthia H.; Henry Gleitman; and Lila R. Gleitman. 1991. On the semantic content of subcategorization frames. Cognitive Psychology 23(3).331-92. DOI: 10 .1016/0010-0285(91)90013-E.

Fisher, Cynthia; KyOng-Sun Jin; and Rose M. Scott. 2019. The developmental origins of syntactic bootstrapping. Topics in Cognitive Science, early view. DOI: 10.1111/tops .12447 .

Giannakidou, Anastasia. 1997. The landscape of polarity items. Groningen: University of Groningen dissertation.

Gillette, Jane; Henry Gleitman; Lila Gleitman; and Anne Lederer. 1999. Human simulations of vocabulary learning. Cognition 73(2).135-76. DOI: 10.1016/S0010 -0277(99)00036-0.

Gleason, JeAn Berko. 1980. The acquisition of social speech: Routines and politeness formulas. Language: Social psychological perspectives, ed. by Howard Giles, W. Peter Robinson, and Philip M. Smith, 21-28. Oxford: Pergamon.

Gleitman, Lila. 1990. The structural sources of verb meanings. Language Acquisition 1(1).3-55. DOI: 10.1207/s15327817la0101_2.

Gleitman, Lila; Kimberly Cassidy; Rebecca Nappa; Anna Papafragou; and John C. Trueswell. 2005. Hard words. Language Learning and Development 1(1).23-64. DOI: $10.1207 / \mathrm{s} 1547334111 \mathrm{~d} 0101 \_4$.

HaCQuard, Valentine. 2014. Bootstrapping attitudes. Proceedings of Semantics and Linguistic Theory (SALT) 24.330-52. DOI: 10.3765/salt.v24i0.2434.

HaCQuard, Valentine, and JefFrey Lidz. 2019. Children's attitude problems: Bootstrapping verb meaning from syntax and pragmatics. Mind \& Language 34(1).73-96. DOI: 10.1111/mila.12192.

Halberda, Justin. 2003. The development of a word-learning strategy. Cognition 87(1). B23-B34. DOI: 10.1016/S0010-0277(02)00186-5.

Hansen, MikKel B. 2010. If you know something, say something: Young children's problem with false beliefs. Frontiers in Psychology 1:23. DOI: 10.3389/fpsyg.2010.00023.

Harrigan, Kaitlyn; Valentine Hacquard; and JefFrey Lidz. 2015. Syntactic bootstrapping in the acquisition of attitude verbs: Think, want and hope. West Coast Conference on Formal Linguistics (WCCFL) 33.196-206. Online: http://www.lingref.com /cpp/wccfl/33/paper3239.pdf.

Harrigan, Kaitlyn; Valentine Hacquard; and Jeffrey Lidz. 2018. Three-year-olds' understanding of desire reports is robust to conflict. Frontiers in Psychology 9:119. DOI: $10.3389 /$ fpsyg.2018.00119.

He, Angela Xiaoxue, and Jeffrey Lidz. 2017. Verb learning in 14- and 18-month-old English-learning infants. Language Learning and Development 13(3).335-56. DOI: 10 $.1080 / 15475441.2017 .1285238$.

Helming, Katharina A.; Brent Strickland; and Pierre Jacob. 2014. Making sense of early false-belief understanding. Trends in Cognitive Sciences 18(4).167-70. DOI: 10 .1016/j.tics.2014.01.005.

HoOPER, JOAN B. 1975. On assertive predicates. Syntax and semantics, vol. 4, ed. by John P. Kimball, 91-124. New York: Academic Press.

Huang, Nick; Chia-Hsuan Liao; Valentine Hacquard; and Jeffrey Lidz. 2018. Learning attitude verb meanings in a morphosyntactically-poor language. Proceedings of the Boston University Conference on Language Development (BUCLD) 42.359-73. Online: http://www.lingref.com/bucld/42/BUCLD42-28.pdf.

JAEGER, T. FLORIAN. 2008. Categorical data analysis: Away from ANOVAs (transformation or not) and towards logit mixed models. Journal of Memory and Language 59(4).43446. DOI: 10.1016/j.jml.2007.11.007. 
Johnson, Carl Nils, and Michael P. Maratsos. 1977. Early comprehension of mental verbs: Think and know. Child Development 48(4).1743-47. DOI: 10.2307/1128549.

KNUDSEN, Birgit, and UlF LiszowsKi. 2012. Eighteen- and 24-month-old infants correct others in anticipation of action mistakes. Developmental Science 15(1).113-22. DOI: 10.1111/j.1467-7687.2011.01098.x.

Kovács, Ágnes Melinda; ERnő Téglas; and Ansgar Denis Endress. 2010. The social sense: Susceptibility to others' beliefs in human infants and adults. Science 330(6012). 1830-34. DOI: 10.1126/science.1190792.

Kutner, Michael; Christopher Nachtsheim; John Neter; and William Li. 2004. Applied linear statistical models. 5th edn. Boston: McGraw-Hill/Irwin.

Landau, Barbara, and Lila R. Gleitman. 1985. Language and experience: Evidence from the blind child. Cambridge, MA: Harvard University Press.

Lewis, Shevaun; Valentine Hacquard; and Jeffrey Lidz. 2012. The semantics and pragmatics of belief reports in preschoolers. Proceedings of Semantics and Linguistic Theory (SALT) 22.247-67. DOI: 10.3765/salt.v22i0.3085.

Lewis, Shevaun; Valentine HacQuard; and JefFrey Lidz. 2017. 'Think' pragmatically: Children's interpretation of belief reports. Language Learning and Development 13(4). 357-74. DOI: 10.1080/15475441.2017.1296768.

Lidz, JefFrey; Henry Gleitman; and Lila Gleitman. 2003. Understanding how input matters: Verb learning and the footprint of universal grammar. Cognition 87(3).151-78. DOI: $10.1016 / \mathrm{S} 0010-0277(02) 00230-5$.

MacWhinney, BRIAn. 2000. The CHILDES project: Tools for analyzing talk. Mahwah, NJ: Lawrence Erlbaum.

Markman, Ellen M., and Gwyn F. Wachtel. 1988. Children's use of mutual exclusivity to constrain the meanings of words. Cognitive Psychology 20(2).121-57. DOI: 10.1016 /0010-0285(88)90017-5.

Mervis, Carolyn, and Jacquelyn Bertrand. 1994. Acquisition of the novel name-nameless category (N3C) principle. Child Development 65(6).1646-62. DOI: 10.1111/j.1467 -8624.1994.tb00840.x.

Moore, Chris; Christopher Jarrold; James Russell; Alistair Lumb; Felicity Sapp; and Fiona MacCallum. 1995. Conflicting desire and the child's theory of mind. Cognitive Development 10(4).467-82. DOI: 10.1016/0885-2014(95)90023-3.

Moyer, Morgan; Kaitlyn Harrigan; Valentine Hacquard; and Jefrrey Lidz. 2015. 2-year-olds' comprehension of personal pronouns. Boston University Conference on Language Development (BUCLD) Online Proceedings Supplement 39. Online: http:// www.bu.edu/bucld/files/2015/06/Moyer.pdf.

Naigles, Letitia. 1990. Children use syntax to learn verb meanings. Journal of Child Language 17(2).357-74. DOI: 10.1017/S0305000900013817.

NaigLes, Letitia. 1996. The use of multiple frames in verb learning via syntactic bootstrapping. Cognition 58(2).221-51. DOI: 10.1016/0010-0277(95)00681-8.

Naigles, Letitia; Henry Gleitman; and Lila Gleitman. 1993. Children acquire word meaning components from syntactic evidence. Language and cognition: A developmental perspective, ed. by Esther Dromi, 104-40. New York: Ablex.

Onishi, Kristine H., and RenÉe BaillargeOn. 2005. Do 15-month-old infants understand false belief? Science 308(5719).255-58. DOI: 10.1126/science.1107621.

Papafragou, Anna; Kimberly Cassidy; and Lila Gleitman. 2007. When we think about thinking: The acquisition of belief verbs. Cognition 105(1).125-65. DOI: 10.1016/j .cognition.2006.09.008.

Perner, Josef, and Ted Ruffman. 2005. Infants' insight into the mind: How deep? Science 308(5719).214-16. DOI: 10.1126/science.1111656.

Perner, Josef; Manuel Sprung; Petra Zauner; and Hubert Haider. 2003. Want that is understood well before say that, think that, and false belief: A test of de Villiers's linguistic determinism on German-speaking children. Child Development 74(1).179-88. DOI: 10.1111/1467-8624.t01-1-00529.

Perner, Josef; Petra Zauner; and Manuel Sprung. 2005. What does 'that' have to do with point of view? Conflicting desires and 'want' in German. Why language matters for theory of mind, ed. by Janet Wilde Astington and Jodie A. Baird, 220-44. New York: Oxford University Press. DOI: 10.1093/acprof:oso/9780195159912.003 .0011 . 
PeSETSKy, DAVID. 1992. Zero syntax II: Infinitival complementation. Cambridge, MA: MIT, MS.

Pinker, Steven. 1989. Learnability and cognition. Cambridge, MA: MIT Press.

Portner, Paul. 1992. Situation theory and the semantics of propositional expressions. Amherst: University of Massachusetts Amherst dissertation.

RAKOCZY, HANNES. 2010. Executive function and the development of belief-desire psychology. Developmental Science 13(4).648-61. DOI: 10.1111/j.1467-7687.2009.00922.x.

Rakoczy, Hannes; Felix Warneken; and Michael Tomasello. 2007. 'This way!', 'No! That way!'-3-year-olds know that two people can have mutually incompatible desires. Cognitive Development 22(1).47-68. DOI: 10.1016/j.cogdev.2006.08.002.

RePaChOli, BETTY M., and Alison GopNiK. 1997. Early reasoning about desires: Evidence from 14- and 18-month-olds. Developmental Psychology 33(1).12-21. DOI: 10.1037 /0012-1649.33.1.12.

Rubio-Fernández, Paula, and Bart Geurts. 2013. How to pass the false-belief task before your fourth birthday. Psychological Science 24(1).27-33. DOI: 10.1177/09567976 12447819.

Scheffler, Tatjana. 2008. Semantic operators in different dimensions. Philadelphia: University of Pennsylvania dissertation.

Scott, Rose M., and Cynthia Fisher. 2009. Two-year-olds use distributional cues to interpret transitivity-alternating verbs. Language and Cognitive Processes 24(6).777803. DOI: $10.1080 / 01690960802573236$.

Searle, John. 1975. Indirect speech acts. Syntax and semantics, vol. 3: Speech acts, ed. by Peter Cole and Jerry L. Morgan, 59-82. New York: Academic Press.

Searle, John, and Daniel VANDERVEken. 1985. Foundations of illocutionary logic. Cambridge: Cambridge University Press.

Simons, Mandy. 2007. Observations on embedding verbs, evidentiality, and presupposition. Lingua 117(6).1034-56. DOI: 10.1016/j.lingua.2006.05.006.

Southgate, Victoria; Atsushi Senju; and Gergely Csibra. 2007. Action anticipation through attribution of false belief by 2-year-olds. Psychological Science 18(7).587-92. DOI: $10.1111 / \mathrm{j} .1467-9280.2007 .01944 . x$.

Sowalsky, Emily; Valentine Hacquard; and Tom Roeper. 2009. Is PP opacity on the path to false belief? Generative Approaches to Language Acquisition North America (GALANA 2008) 3.263-61. Online: http://www.lingref.com/cpp/galana/3/paper2325 .pdf.

Surian, Luca; Stefania Caldi; and Dan Sperber. 2007. Attribution of beliefs by 13month-old infants. Psychological Science 18(7).580-86. DOI: 10.1111/j.1467-9280 .2007.01943.x.

TRuCKenBrodt, Hubert. 2006. On the semantic motivation of syntactic verb movement to C in German. Theoretical Linguistics 32(3).257-306. DOI: 10.1515/TL.2006.018.

Urmson, James Opie. 1952. Parenthetical verbs. Mind 61(244).480-96. Online: https:// www.jstor.org/stable/2251029.

van Dooren, Annemarie; Anouk Dieuleveut; Ailís Cournane; and Valentine HaCQUARD. 2017. Learning what must and can must and can mean. Proceedings of the Amsterdam Colloquium 21.225-34. Online: https://semanticsarchive.net/Archive/jZiM2FhZ /AC2017-Proceedings.pdf.

Villalta, Elisabeth. 2000. Spanish subjunctive clauses require ordered alternatives. Proceedings of Semantics and Linguistic Theory (SALT) 10.239-56. DOI: 10.3765/salt .v10i0.3123.

Villalta, Elisabeth. 2008. Mood and gradability: An investigation of the subjunctive mood in Spanish. Linguistics and Philosophy 31.467-522. DOI: 10.1007/s10988-008 -9046-x.

Wellman, Henry M., and Mita Banerjee. 1991. Mind and emotion: Children's understanding of the emotional consequences of beliefs and desires. British Journal of Developmental Psychology 9(2).191-214. DOI: 10.1111/j.2044-835X.1991.tb00871.x.

Wellman, Henry M., and Karen Bartsch. 1988. Young children's reasoning about beliefs. Cognition 30(3).239-77. DOI: 10.1016/0010-0277(88)90021-2.

Wellman, Henry M.; David Cross; and Julanne Watson. 2001. Meta-analysis of theory-of-mind development: The truth about false belief. Child Development 72(3).65584. DOI: $10.1111 / 1467-8624.00304$. 
Wellman, Henry M., and Jacqueline D. Wooley. 1990. From simple desires to ordinary beliefs: The early development of everyday psychology. Cognition 35(3).245-75. DOI: 10.1016/0010-0277(90)90024-E.

White, Aaron S.; Rachel Dudley; Valentine Hacquard; and Jeffrey Lidz. 2014. Discovering classes of attitude verbs using subcategorization frame distributions. North East Linguistic Society (NELS) 43(2).249-60.

White, Aaron S.; Valentine Hacquard; and Jeffrey Lidz. 2018. Semantic information and the syntax of propositional attitude verbs. Cognitive Science 42(2).416-56. DOI: 10.1111/cogs. 12512 .

White, AAron S., and Kyle Rawlins. 2018. The role of veridicality and facticity in clause selection. North East Linguistic Society (NELS) 48(3).221-34.

Wimmer, Heinz, and Josef Perner. 1983. Beliefs about beliefs: Representation and constraining function of wrong beliefs in young children's understanding of deception. Cognition 13(1).103-28. DOI: 10.1016/0010-0277(83)90004-5.

Woodward, Amanda L. 1998. Infants selectively encode the goal object of an actor's reach. Cognition 69(1).1-34. DOI: 10.1016/S0010-0277(98)00058-4.

Yuan, Sylvia, and Cynthia Fisher. 2009. 'Really? She blicked the baby?': Two-year-olds learn combinatorial facts about verbs by listening. Psychological Science 20(5).61926. DOI: $10.1111 /$ j.1467-9280.2009.02341.x.

\section{Harrigan}

Department of Psychological Sciences

P.O. Box 8795

Williamsburg, VA 23187-8795

[kharrigan@wm.edu]

[hacquard@umd.edu] (Hacquard)

[jlidz@umd.edu] (Lidz)
[Received 3 July 2018; revision invited 2 October 2018; revision received 2 February 2019; revision invited 4 April 2019; revision received 22 May 2019; accepted 25 June 2019] 